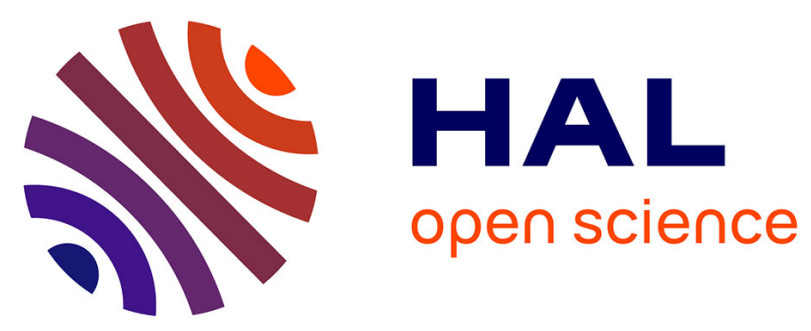

\title{
ANALYTICAL CALCULATION OF PARALLEL DOUBLE EXCITATION AND SPOKE-TYPE PERMANENT-MAGNET MOTORS; SIMPLIFIED VERSUS EXACT MODEL
}

Kamel Boughrara, Thierry Lubin, Rachid Ibtiouen, Mohamed N. Benallal

\section{To cite this version:}

Kamel Boughrara, Thierry Lubin, Rachid Ibtiouen, Mohamed N. Benallal. ANALYTICAL CALCULATION OF PARALLEL DOUBLE EXCITATION AND SPOKE-TYPE PERMANENT-MAGNET MOTORS; SIMPLIFIED VERSUS EXACT MODEL. Progress In Electromagnetics Research B, 2013, 47, pp.145-178. 10.2528/PIERB1211130 . hal-00834001

\section{HAL Id: hal-00834001 https://hal.science/hal-00834001}

Submitted on 13 Jun 2013

HAL is a multi-disciplinary open access archive for the deposit and dissemination of scientific research documents, whether they are published or not. The documents may come from teaching and research institutions in France or abroad, or from public or private research centers.
L'archive ouverte pluridisciplinaire HAL, est destinée au dépôt et à la diffusion de documents scientifiques de niveau recherche, publiés ou non, émanant des établissements d'enseignement et de recherche français ou étrangers, des laboratoires publics ou privés. 


\title{
ANALYTICAL CALCULATION OF PARALLEL DOU- BLE EXCITATION AND SPOKE-TYPE PERMANENT- MAGNET MOTORS; SIMPLIFIED VERSUS EXACT MODEL
}

\section{Kamel Boughrara ${ }^{1,}{ }^{*}$, Thierry Lubin ${ }^{2}$, Rachid Ibtiouen ${ }^{3}$, and Mohamed N. Benallal ${ }^{1}$}

${ }^{1}$ Laboratoire de l'Energie et des Systèmes Intelligents (LESI), Université de Khemis-Miliana, Route de Theniet El-had, KhemisMiliana 44225, Algeria

${ }^{2}$ Groupe de Recherche en Electrotechnique et Electronique de Nancy, Université de Lorraine, GREEN, EA 4366, Vandoeuvre-lès-Nancy F54506, France

${ }^{3}$ Ecole Nationale Polytechnique (LRE-ENP), Algiers, 10, Av. Pasteur, El Harrach, BP 182, 16200, Algeria

\begin{abstract}
This paper deals with the prediction of magnetic field distribution and electromagnetic performances of parallel double excitation and spoke-type permanent magnet (PM) motors using simplified (SM) and exact (EM) analytical models. The simplified analytical model corresponds to a simplified geometry of the studied machines where the rotor and stator tooth-tips and the shape of polar pieces are not taken into account. A 2D analytical solution of magnetic field distribution is established. It involves solution of Laplace's and Poisson's equations in stator and rotor slots, airgap, buried permanent magnets into rotor slots and non magnetic region under magnets. A comparison between the results issued from the simplified model with those from exact model (EM) (which represents a more realistic geometry with stator and rotor tooth-tips and the shape of polar pieces) is done to show the accuracy of the simplified geometry on magnetic field distribution and electromagnetic performances (cogging torque, electromagnetic torque, flux linkage, back-EMF, self and mutual inductances). The analytical results are verified with those issued from finite element method (FEM).
\end{abstract}

Received 13 November 2012, Accepted 12 December 2012, Scheduled 31 December 2012

* Corresponding author: Kamel Boughrara (boughrarakamel@yahoo.fr). 


\section{INTRODUCTION}

Analytical models are useful tools for first evaluations of electrical motors performances and for the first step of design optimization. The aim of this paper is to analytically predict the magnetic field distribution and electromagnetic performances of parallel double excitation and spoke-type PM motors, such as cogging torque, flux linkage, back-EMF, electromagnetic torque, self and mutual inductances, and DC rotor excitation current capability for the control of flux linkage. The proposed analytical model is based on subdomain method. Many authors have proposed analytical simplified and exact models based on subdomain method in order to study the stator slotting effects (with or without tooth-tips) on magnetic field distribution and electromagnetic performances (under no-load and load conditions) in radial inset and surface-mounted permanent magnet motors [1-11]. It was shown that the accuracy of subdomain models is higher than permeance models [12] or conformal transformations models [13-15]. However, there are no authors who applied simplified analytical model for predicting magnetic field and electromagnetic performances in parallel double excitation and spoke-type PM motors. There are only Lin et al. in [13] who calculated magnetic field and cogging torque by conformal mapping with a simplified model of spoketype PM motors.

$\mathrm{Wu}$ et al. [5] have shown recently that a subdomain model which takes into account the stator tooth-tips in surface-mounted permanent magnet motors gives approximately the same results in terms of electromagnetic performances as the one which neglects stator toothtips. This is due to the fact that there are only tooth-tips in stator slots for surface-mounted permanent magnet motors. For parallel double excitation and spoke-type PM machines which are studied here, toothtips are localized in three regions: stator slots, rotor DC excitation slots and magnet slots as shown in Fig. 2. As will be shown in this paper, the mutual influence between all of these tooth-tips can modify considerably the electromagnetic performances. It depends on the dimension of the tooth-tip openings compared to the slot openings.

In this paper, an exact analytical prediction based on subdomain model for the computation of magnetic field distribution and electromagnetic performances in parallel double excitation and spoketype tangential PM machines with distributed windings integer slot per pole and per phase machine is presented. It involves the solution of Poisson's and Laplace's equations in stator slots, buried permanent magnets placed in slots, rotor double excitation slots, air gap and non magnetic region under permanent magnets. The analytical model 
developed in this paper, which does not take into account the stator and rotor tooth-tips and the shape of polar piece, is a simplification of the exact model (EM) presented recently by the authors [16]. A comparison between the results issued from the simplified model (SM) with those from exact model (EM) [16] is done to show the effect of the simplified geometry on magnetic field distribution and electromagnetic performances (cogging torque, electromagnetic torque, flux linkage, back-EMF, self and mutual inductances). It is important to note that only magnetic field distribution is calculated in [16]. The results obtained with analytical models are then compared to those found by the finite element method (FEM).

\section{MAGNETIC FIELD SOLUTION IN PARALLEL DOUBLE EXCITATION PM MOTOR}

Figures 1 and 2 show the machine model where region I represents the air gap, region II the magnets, region III the stator slots, region IV a non magnetic material under magnets and region $\mathrm{V}$ the rotor excitation slots. The model is formulated in two-dimensional polar coordinates with the following assumptions.

- The stator and rotor cores are assumed to be infinitely permeable

- Eddy current effects are neglected

- The axial length of the machine is infinite, i.e., end effects are neglected

- The current density has only one component along the $z$-axis

- The stator and rotor slots have radial sides

The partial differential equations for magnetic field in term of vector potential $A$ which has only one component in the $z$ direction and is not dependent on the $z$ coordinate, can be expressed by

$$
\begin{aligned}
\nabla^{2} A & =0, \quad \text { in regions } \mathrm{I} \text { and } \mathrm{IV} \\
\nabla^{2} A & =-\mu_{0} \nabla \times M, \quad \text { in region } \mathrm{II} \\
\nabla^{2} A & =-\mu_{0} J, \quad \text { in region } \mathrm{III} \\
\nabla^{2} A & =-\mu_{0} J_{r}, \quad \text { in region } \mathrm{V}
\end{aligned}
$$

where $M$ is the magnetization of permanent magnets, $J$ the stator slots current density, $J_{r}$ the excitation rotor slots current density and $\mu_{0}$ the permeability of vacuum.

The field vectors $B$ and $H$, in the different regions, are coupled by

$$
\mathbf{B}=\boldsymbol{\mu}_{\mathbf{0}} \mathbf{H}, \quad \text { in regions I, III, IV and V }
$$




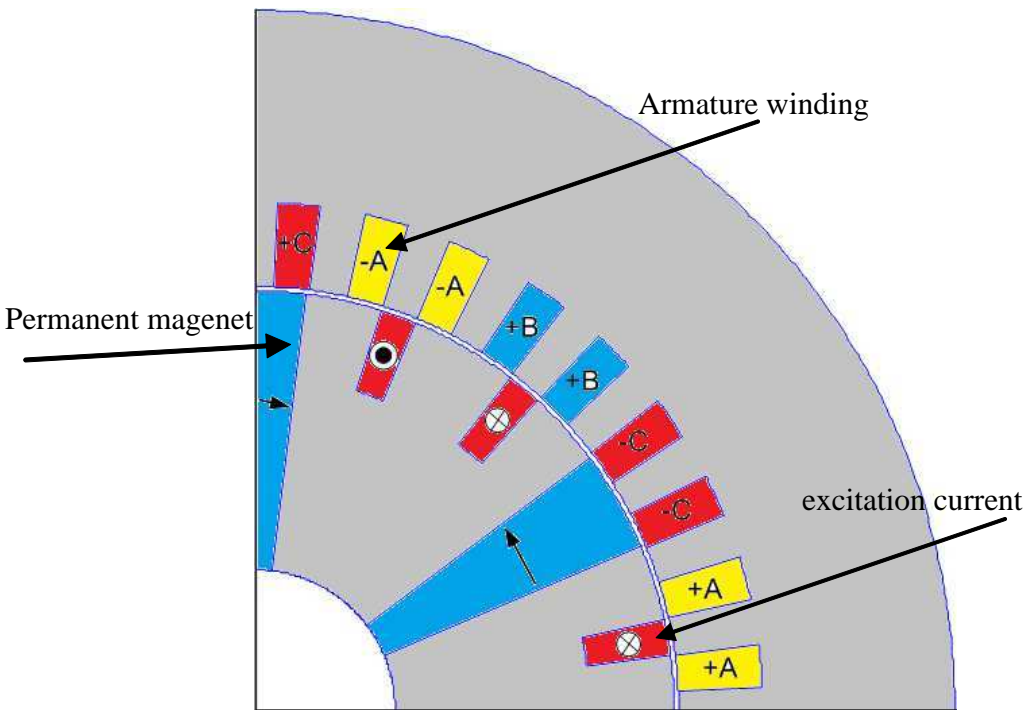

Figure 1. Studied parallel double excitation PM machine (1/4 of the machine).

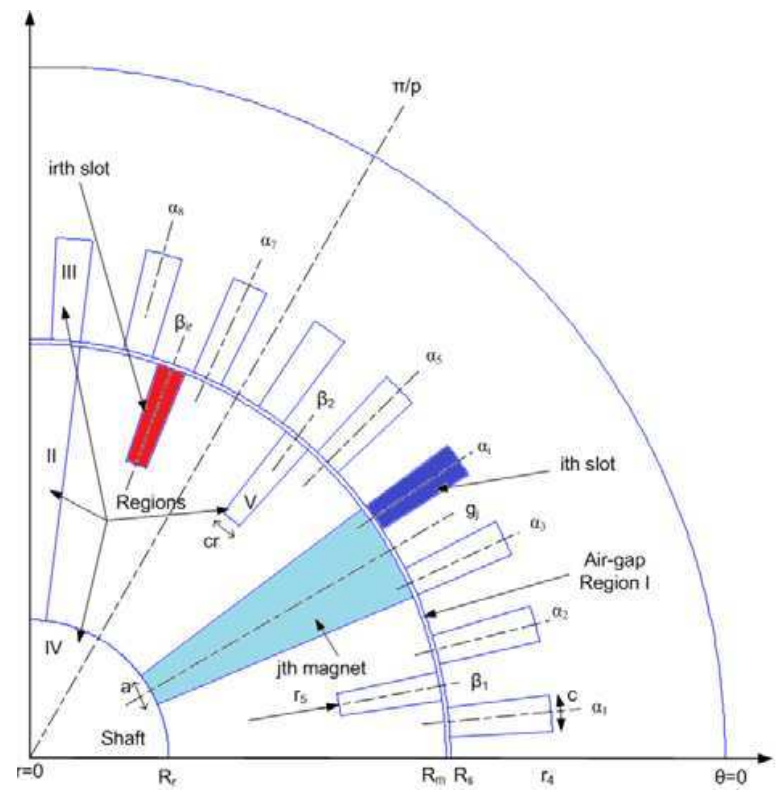

Figure 2. Studied model (1/4 of the machine). 
where $B_{r}=\mu_{0} H_{r}, B_{\theta}=\mu_{0} H_{\theta}$

$$
\mathrm{B}=\boldsymbol{\mu}_{\mathbf{0}} \boldsymbol{\mu}_{\mathbf{r}} \mathbf{H}+\boldsymbol{\mu}_{\mathbf{0}} \mathrm{M}, \quad \text { in region II }
$$

where $B_{r}=\mu_{0} \mu_{r} H_{r}+\mu_{0} M_{r}, B_{\theta}=\mu_{0} \mu_{r} H_{\theta}+\mu_{0} M_{\theta}$ and $\mu_{r}$ is the relative recoil permeability of permanent magnets. Radial and circumferential flux density components are deduced from $A$ by

$$
B_{r}=\frac{1}{r} \frac{\partial A}{\partial \theta}, \quad B_{\theta}=-\frac{\partial A}{\partial r}
$$

\subsection{General Solution of Poisson's Equation in Stator Slot Subdomain (Region III)}

In each slot subdomain (i) of region III (Fig. 3), we have to solve Poisson's equation

$$
\frac{\partial^{2} A I I I_{i}}{\partial r^{2}}+\frac{1}{r} \frac{\partial A I I I_{i}}{\partial r}+\frac{1}{r^{2}} \frac{\partial^{2} A I I I_{i}}{\partial \theta^{2}}=-\mu_{0} J_{i}
$$

where $J_{i}$ is the current density in the slot $i$.

As shown in Fig. 3, the $i$ th stator slot subdomain where $i$ varies from 1 to $Q_{s}\left(Q_{s}\right.$ is the number of stator slots) is associated with boundary conditions at the bottom and at each sides of the slot as

$$
\begin{gathered}
\left.\frac{\partial A I I I_{i}}{\partial \theta}\right|_{\theta=\alpha_{i}-\frac{c}{2}}=0 \text { and }\left.\quad \frac{\partial A I I I_{i}}{\partial \theta}\right|_{\theta=\alpha_{i}+\frac{c}{2}}=0 \\
\left.\frac{\partial A I I I_{i}}{\partial r}\right|_{r=r_{4}}=0
\end{gathered}
$$

where $\alpha_{i}$ is the angular position of the $i$ th slot and $c$ the slot opening in radian.

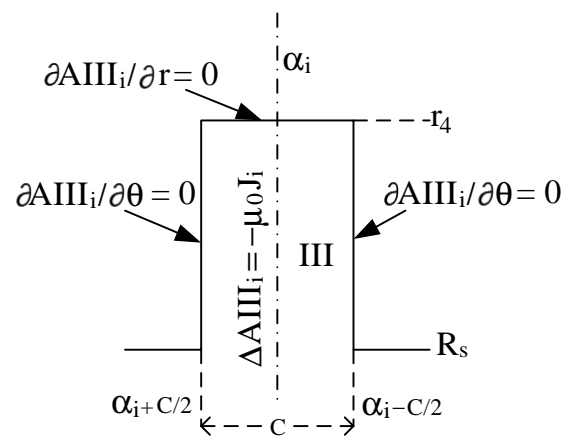

Figure 3. $i$ th stator slot subdomain.

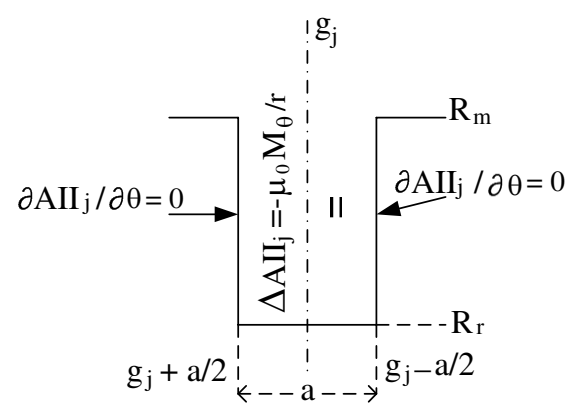

Figure 4. $j$ th permanent magnet subdomain. 
From above boundary conditions (9) and (10), the solution of (8) using the method of separation of variables is

$$
\begin{aligned}
\operatorname{AIII}_{i}(r, \theta)= & C_{i, 0}+\frac{1}{2} \mu_{0} J_{i} r_{4}^{2} \ln (r)-\frac{1}{4} \mu_{0} J_{i} r^{2} \\
& +\sum_{m=1}^{\infty} C_{i, m}\left[\left(\frac{r}{r_{4}}\right)^{\frac{m \pi}{c}}-\left(\frac{r}{r_{4}}\right)^{-\frac{m \pi}{c}}\right] \cos \left(\frac{m \pi}{c}\left(\theta-\alpha_{i}+\frac{c}{2}\right)\right)
\end{aligned}
$$

where $m$ is a positive integer.

\subsection{General Solution of Poisson's Equation in Permanent Magnet Subdomain (Region II)}

In each permanent magnet subdomain $(j)$ of region II (Figs. 2 and 4 ), we have to solve Poisson's Equation (2). The magnetization of parallel double excitation motor is considered purely tangential. Equation (2) is then reduced to

$$
\frac{\partial^{2} A I I_{j}}{\partial r^{2}}+\frac{1}{r} \frac{\partial A I I_{j}}{\partial r}+\frac{1}{r^{2}} \frac{\partial^{2} A I I_{j}}{\partial \theta^{2}}=-\mu_{0} \frac{M_{\theta}}{r}
$$

where $M_{\theta}=M_{j}=(-1)^{j} \frac{B_{r e m}}{\mu_{0}}$.

For a $2 p$ poles machine, $j$ varies from 1 to $2 p$ and $B_{r e m}$ is the remanence of the magnets.

As shown in Fig. 4, the $j$ th magnet subdomain (region II) is associated with the following boundary conditions

$$
\left.\frac{\partial A I I_{j}}{\partial \theta}\right|_{\theta=g_{j}-\frac{a}{2}}=0 \quad \text { and }\left.\quad \frac{\partial A I I_{j}}{\partial \theta}\right|_{\theta=g_{j}+\frac{a}{2}}=0
$$

where $g_{j}$ is the angular position of the $j t h$ magnet and a the magnet opening in radian.

From above boundary conditions (13), the general solution of (12) using the method of separation of variables is given by

$$
\begin{aligned}
A I I_{j}(r, \theta)= & A 5_{j, 0}+A 6_{j, 0} \ln (r)-\mu_{0} M_{j} r \\
& +\sum_{m=1}^{\infty}\left(A 5_{j, m} r^{-\frac{m \pi}{a}}+A 6_{j, m} r^{\frac{m \pi}{a}}\right) \cos \left(\frac{m \pi}{a}\left(\theta-g_{j}+\frac{a}{2}\right)\right)
\end{aligned}
$$

\subsection{General Solution of Laplace's Equation in Airgap Subdomain (Region I)}

The Laplace Equation (1) in the airgap subdomain (region I) which is an annular domain delimited by the radii $R_{m}$ and $R_{s}$ (Fig. 2) is given by

$$
\frac{\partial^{2} A I}{\partial r^{2}}+\frac{1}{r} \frac{\partial A I}{\partial r}+\frac{1}{r^{2}} \frac{\partial^{2} A I}{\partial \theta^{2}}=0
$$


For the studied machine with integer slot per pole and per phase, the periodicity of the problem is $\frac{2 \pi}{p}$ and the solution of Equation (15) is

$$
\begin{aligned}
A I(r, \theta)= & +\sum_{n=1}^{\infty}\left(A 1_{n} r^{n p}+A 2_{n} r^{-n p}\right) \sin (n p \theta) \\
& +\left(A 3_{n} r^{n p}+A 4_{n} r^{-n p}\right) \cos (n p \theta)
\end{aligned}
$$

where $n$ is a positive integer.

\subsection{General Solution of Laplace's Equation in the Non-magnetic Subdomain (Region IV)}

The Laplace's Equation (1) in the non-magnetic subdomain (region IV) is given by

$$
\frac{\partial^{2} A I V}{\partial r^{2}}+\frac{1}{r} \frac{\partial A I V}{\partial r}+\frac{1}{r^{2}} \frac{\partial^{2} A I V}{\partial \theta^{2}}=0
$$

The general solution of (17) is

$$
\begin{aligned}
\operatorname{AIV}(r, \theta)= & \sum_{n=1}^{\infty}\left(A 7_{n} r^{n p}+A 8_{n} r^{-n p}\right) \sin (n p \theta) \\
& +\left(A 9_{n} r^{n p}+A 10_{n} r^{-n p}\right) \cos (n p \theta)
\end{aligned}
$$

The magnetic vector potential must be finite in region IV when $r=0$. Therefore, the constants $A 8_{n}$ and $A 10_{n}$ are equals to zero and (18) is reduced to

$$
A I V(r, \theta)=\sum_{n=1}^{\infty} r^{n p} A 7_{n} \sin (n p \theta)+r^{n p} A 9_{n} \cos (n p \theta)
$$

\subsection{General Solution of Poisson's Equation in Rotor Excitation Coil Slot Subdomain (Region V)}

In each rotor slot subdomain (ir) of region V, we have to solve Poisson's Equation (20)

$$
\frac{\partial^{2} A V_{i r}}{\partial r^{2}}+\frac{1}{r} \frac{\partial A V_{i r}}{\partial r}+\frac{1}{r^{2}} \frac{\partial^{2} A V_{i r}}{\partial \theta^{2}}=-\mu_{0} J_{r_{i r}}
$$

where $J r_{i r}$ is the current density in rotor slot $i r$.

As shown in Fig. 5, the $i r$ th slot subdomain where $i r$ varies from 1 to $N_{r}\left(N_{r}\right.$ is total number of rotor excitation slots) is associated with the following boundary conditions

$$
\begin{gathered}
\left.\frac{\partial A V_{i r}}{\partial \theta}\right|_{\theta=\beta_{i r}-\frac{c r}{2}}=0 \text { and }\left.\quad \frac{\partial A V_{i r}}{\partial \theta}\right|_{\theta=\beta_{i r}+\frac{c r}{2}}=0 \\
\left.\frac{\partial A V_{i r}}{\partial r}\right|_{r=r_{5}}=0
\end{gathered}
$$




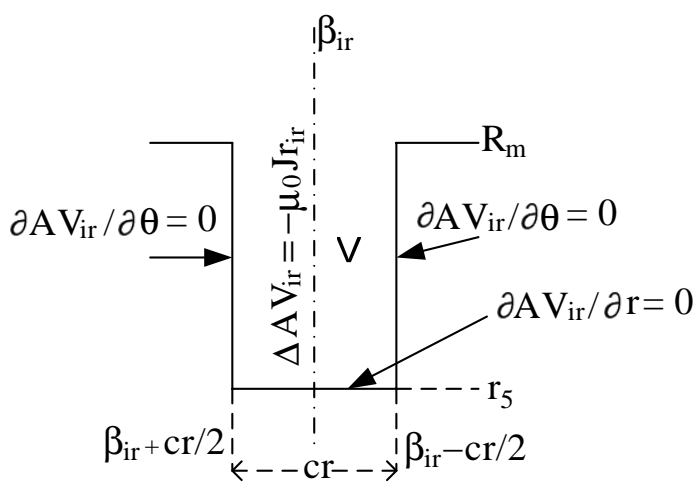

Figure 5. irth rotor slot subdomain.

where $\beta_{i r}$ is the angular position of the $i r$ th slot and $c r$ the rotor slot opening in radian.

From the above boundary conditions (21) and (22), the solution of (20) using the method of separation of variables is

$$
\begin{aligned}
A V_{i r}(r, \theta)= & C 1_{i r, 0}+\frac{1}{2} \mu_{0} J_{f_{i r}} r_{5}^{2} \ln (r)-\frac{1}{4} \mu_{0} J_{f_{i r}} r^{2} \\
& +\sum_{m=1}^{\infty} C 1_{i r, m}\left[\left(\frac{r}{r_{5}}\right)^{\frac{m \pi}{c_{r}}}-\left(\frac{r}{r_{5}}\right)^{-\frac{m \pi}{c_{r}}}\right] \cdot \cos \left(\frac{m \pi}{c_{r}}\left(\theta-\beta_{i r}+\frac{c_{r}}{2}\right)\right)(23)
\end{aligned}
$$

\section{BOUNDARY AND INTERFACE CONDITIONS}

To determine Fourier series unknown constants $A 1_{n}, A 2_{n}, A 3_{n}, A 4_{n}$, $A 5_{j, 0}, A 6_{j, 0}, A 5_{j, m}, A 6_{j, m}, A 7_{n}, A 9_{n}, C_{i, 0}, C_{i, m}, C 1_{i r, 0}, C 1_{i r, m}$, boundary and interface conditions should be introduced. The interface conditions must satisfy the continuity of the radial component of the flux density and the continuity of the tangential component of the magnetic field. The first condition could be replaced by the continuity of $A$.

The interface conditions between regions IV and II at $R_{r}$ are

$$
A I I_{j}\left(R_{r}, \theta\right)=A I V\left(R_{r}, \theta\right)
$$

where $g_{j}-\frac{a}{2} \leq \theta \leq g_{j}+\frac{a}{2}$.

$$
H I I_{\theta_{j}}\left(R_{r}, \theta\right)=H I V_{\theta}\left(R_{r}, \theta\right)
$$

where $g_{j}-\frac{a}{2} \leq \theta \leq g_{j}+\frac{a}{2}$. $H I V_{\theta}\left(R_{r}, \theta\right)=0$ elsewhere.

The interface condition between regions I and II at $R_{m}$ is

$$
A I I_{j}\left(R_{m}, \theta\right)=A I\left(R_{m}, \theta\right)
$$


where $g_{j}-\frac{a}{2} \leq \theta \leq g_{j}+\frac{a}{2}$.

The interface condition between regions $\mathrm{I}$ and $\mathrm{V}$ at $R_{m}$ is

$$
A I\left(R_{m}, \theta\right)=A V_{i r}\left(R_{m}, \theta\right)
$$

where $\beta_{i r}-\frac{c r}{2} \leq \theta \leq \beta_{i r}+\frac{c r}{2}$.

The interface conditions between regions I, V and II at $R_{m}$ are

$$
H I_{\theta}\left(R_{m}, \theta\right)=H I I_{\theta_{j}}\left(R_{m}, \theta\right)
$$

for $g_{j}-\frac{a}{2} \leq \theta \leq g_{j}+\frac{a}{2}$ and $H I_{\theta}\left(R_{m}, \theta\right)=H V_{\theta_{i} r}\left(R_{m}, \theta\right)$. For $\beta_{i r}-\frac{c r}{2} \leq \theta \leq \beta_{i r}+\frac{c r}{2}$ and $H I_{\theta}\left(R_{m}, \theta\right)=0$ elsewhere.

The interface conditions between regions I and III at $R_{s}$ are

$$
A I\left(R_{s}, \theta\right)=A I I I_{i}\left(R_{s}, \theta\right)
$$

where $\alpha_{i}-\frac{c}{2} \leq \theta \leq \alpha_{i}+\frac{c}{2}$.

$$
H I_{\theta}\left(R_{s}, \theta\right)=H I I I_{\theta_{i}}\left(R_{s}, \theta\right)
$$

where $\alpha_{i}-\frac{c}{2} \leq \theta \leq \alpha_{i}+\frac{c}{2}$. $H I_{\theta}\left(R_{s}, \theta\right)=0$ elsewhere.

Interface conditions (24) to (30) concern regions with different subdomain frequencies which need Fourier series expansions to satisfy equalities of vector potential and magnetic field at each interface radius.

According to Fourier series expansion, from (24) we obtain two equations as

$$
\begin{aligned}
& A 5_{j, 0}+A 6_{j, 0} \ln \left(R_{r}\right)-M_{j} \mu_{0} R_{r} \\
= & \frac{1}{a} \int_{g_{j}-\frac{a}{2}}^{g_{j}+\frac{a}{2}} A I V\left(R_{r}, \theta\right) d \theta \\
& A 5_{j, m} R_{r}^{-\left(\frac{m \pi}{a}\right)}+A 6_{j, m} R_{r}^{\left(\frac{m \pi}{a}\right)} \\
= & \frac{2}{a} \int_{g_{j}-\frac{a}{2}}^{g_{j}+\frac{a}{2}} A I V\left(R_{r}, \theta\right) \cos \left(\frac{m \pi}{a}\left(\theta-g_{j}+\frac{a}{2}\right)\right) d \theta
\end{aligned}
$$

Interface condition (25) gives

$$
\begin{aligned}
& \left(\frac{n p}{\mu_{0}}\right)\left(-A 7_{n} R_{r}^{n p-1}\right)=\frac{1}{\pi} \sum_{j=1}^{2 p} \int_{g_{j}-\frac{a}{2}}^{g_{j}+\frac{a}{2}} H I I_{\theta j}\left(R_{r}, \theta\right) \sin (n p \theta) d \theta \\
& \left(\frac{n p}{\mu_{0}}\right)\left(-A 9_{n} R_{r}^{n p-1}\right)=\frac{1}{\pi} \sum_{j=1}^{2 p} \int_{g_{j}-\frac{a}{2}}^{g_{j}+\frac{a}{2}} H I I \theta_{j}\left(R_{r}, \theta\right) \cos (n p \theta) d \theta
\end{aligned}
$$


Fourier series expansion of interface condition (26) between regions II and $\mathrm{I}$ at radius $R_{m}$ gives

$$
\begin{aligned}
& A 5_{j, 0}+A 6_{j, 0} \ln \left(R_{m}\right)-M_{j} \mu_{0} R_{m} \\
= & \frac{1}{a} \int_{g_{j}-\frac{a}{2}}^{g_{j}+\frac{a}{2}} A I\left(R_{m}, \theta\right) d \theta \\
& A 5_{j, m} R_{m}^{-\left(\frac{m \pi}{a}\right)}+A 6_{j, m} R_{m}^{\left(\frac{m \pi}{a}\right)} \\
= & \frac{2}{a} \int_{g_{j}-\frac{a}{2}}^{g_{j}+\frac{a}{2}} A I\left(R_{r}, \theta\right) \cos \left(\frac{m \pi}{a}\left(\theta-g_{j}+\frac{a}{2}\right)\right) d \theta
\end{aligned}
$$

From interface condition (27), we obtain

$$
\begin{aligned}
& C 1_{i r, 0}+\frac{1}{2} \mu_{0} J r_{i r} r_{5}^{2} \ln \left(R_{m}\right)-\frac{1}{4} \mu_{0} J r_{i r} R_{m}^{2} \\
= & \frac{1}{c r} \int_{\beta_{i r}-\frac{c r}{2}}^{\beta_{i r}+\frac{c r}{2}} A I\left(R_{m}, \theta\right) d \theta \\
& C 1_{i r, m}\left(\left(\frac{R_{m}}{r_{5}}\right)^{\frac{m \pi}{c r}}-\left(\frac{R_{m}}{r_{5}}\right)^{-\frac{m \pi}{c r}}\right) \\
= & \frac{2}{c r} \int_{\beta_{i r}-\frac{c r}{2}}^{\beta_{i r}+\frac{c r}{2}} A I\left(R_{m}, \theta\right) \cos \left(\frac{m \pi}{c r}\left(\theta-\beta_{i r}+\frac{c r}{2}\right)\right) d \theta
\end{aligned}
$$

Fourier series expansion of interface condition (28) gives

$$
\begin{aligned}
& \frac{n p}{\mu_{0}}\left(-A 1_{n} R_{m}^{n p-1}+A 2_{n} R_{m}^{-n p-1}\right)=\frac{1}{\pi} \sum_{j=1}^{2 p} \int_{g_{j}-\frac{a}{2}}^{g_{j}+\frac{a}{2}} H I I_{\theta j}\left(R_{m}, \theta\right) \sin (n p \theta) d \theta \\
& +\frac{1}{\pi} \sum_{i r=1}^{N_{r}} \int_{\beta_{i r}-\frac{c r}{2}}^{\beta_{i r}+\frac{c r}{2}} H V_{\theta i r}\left(R_{m}, \theta\right) \sin (n p \theta) d \theta
\end{aligned}
$$




$$
\begin{aligned}
& \frac{n p}{\mu_{0}}\left(-A 3_{n} R_{m}^{n p-1}+A 4_{n} R_{m}^{-n p-1}\right)=\frac{1}{\pi} \sum_{j=1}^{2 p} \int_{g_{j}-\frac{a}{2}}^{g_{j}+\frac{a}{2}} H I I_{\theta j}\left(R_{m}, \theta\right) \cos (n p \theta) d \theta \\
& +\frac{1}{\pi} \sum_{i r=1}^{N_{r}} \int_{\beta_{i r}-\frac{c r}{2}}^{\beta_{i r}+\frac{c r}{2}} H V_{\theta i r}\left(R_{m}, \theta\right) \cos (n p \theta) d \theta
\end{aligned}
$$

At radius $R_{s}$, Fourier series expansions of interface condition (29) gives

$$
\begin{aligned}
& C_{i, 0}+\frac{1}{2} \mu_{0} J_{i} r_{4}^{2} \ln \left(R_{s}\right)-\frac{1}{4} \mu_{0} J_{i} R_{s}^{2}=\frac{1}{c} \int_{\alpha_{i}-\frac{c}{2}}^{\alpha_{i}+\frac{c}{2}} A I\left(R_{s}, \theta\right) d \theta \\
& C_{i, m}\left(\left(\frac{R_{s}}{r_{4}}\right)^{\frac{m \pi}{c}}-\left(\frac{R_{s}}{r_{4}}\right)^{-\frac{m \pi}{c}}\right)=\frac{2}{c} \int_{\alpha_{i}-\frac{c}{2}}^{\alpha_{i}+\frac{c}{2}} A I\left(R_{s}, \theta\right) \cos \left(\frac{m \pi}{c}\left(\theta-\alpha_{i}+\frac{c}{2}\right)\right) d \theta(
\end{aligned}
$$

Fourier series expansion of interface condition (30) gives

$$
\begin{aligned}
& \frac{n p}{\mu_{0}}\left(-A 1_{n} R_{s}^{n p-1}+A 2_{n} R_{s}^{-n p-1}\right) \\
= & \frac{1}{\pi} \sum_{i=1}^{Q_{s}} \int_{\alpha_{i}-\frac{c}{2}}^{\alpha_{i}+\frac{c}{2}} H I I I_{\theta i}\left(R_{s}, \theta\right) \sin (n p \theta) d \theta \\
& \frac{n p}{\mu_{0}}\left(-A 3_{n} R_{s}^{n p-1}+A 4_{n} R_{s}^{-n p-1}\right) \\
= & \frac{1}{\pi} \sum_{i=1}^{Q_{s}} \int_{\alpha_{i}-\frac{c}{2}}^{\alpha_{i}+\frac{c}{2}} H I I I_{\theta i}\left(R_{s}, \theta\right) \cos (n p \theta) d \theta
\end{aligned}
$$

Some developments of Equations (31) to (44) are given in Appendix A.

From Equations (31)-(44) we can calculate the 14 coefficients $A 1_{n}$, $A 2_{n}, A 3_{n}, A 4_{n}, A 5_{j, 0}, A 6_{j, 0}, A 5_{j, m}, A 6_{j, m}, A 7_{n}, A 9_{n}, C_{i, 0}, C_{i, m}$, $C 1_{i r, 0}, C 1_{i r, m}$ with a given number of harmonics for $n$ and $m$.

\section{MAGNETIC FIELD SOLUTION IN SPOKE-TYPE PM MOTOR}

Spoke-type PM motor analytical model is a special case of parallel double excitation PM motor model, where region V is omitted (Fig. 6). 


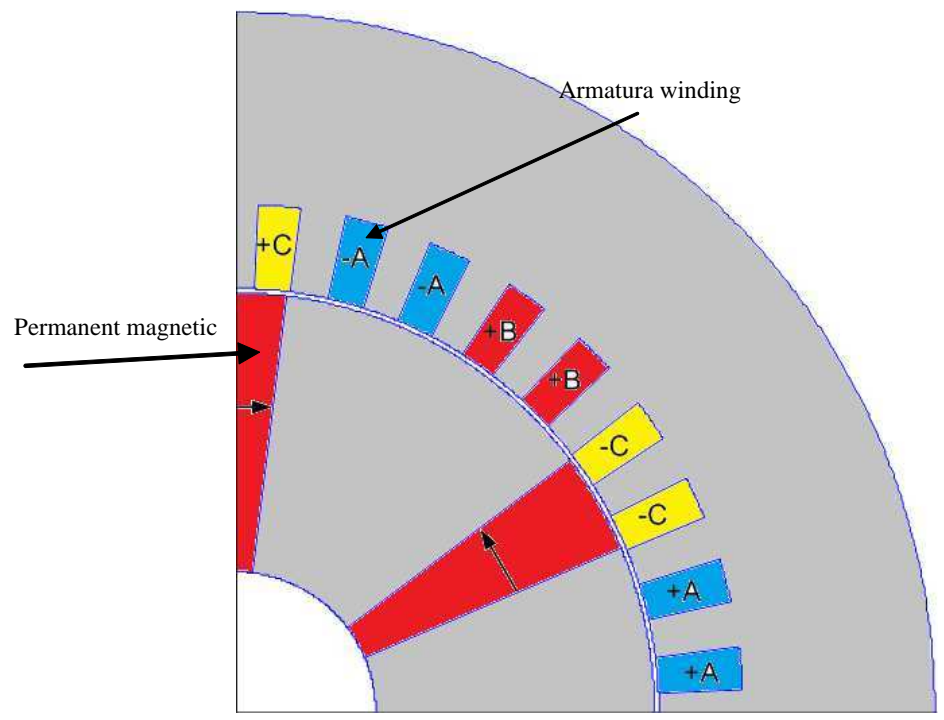

Figure 6. Studied spoke-type PM machine (1/4 of the machine).

Then, Equations (37) and (38) disappear and (39) and (40) are modified respectively as follow:

$\frac{n p}{\mu_{0}}\left(-A 1_{n} R_{m}^{n p-1}+A 2_{n} R_{m}^{-n p-1}\right)=\frac{1}{\pi} \sum_{j=1}^{2 p} \int_{g_{j}-\frac{a}{2}}^{g_{j}+\frac{a}{2}} H I I_{\theta j}\left(R_{m}, \theta\right) \sin (n p \theta) d \theta(45)$
$\frac{n p}{\mu_{0}}\left(-A 3_{n} R_{m}^{n p-1}+A 4_{n} R_{m}^{-n p-1}\right)=\frac{1}{\pi} \sum_{j=1}^{2 p} \int_{g_{j}-\frac{a}{2}}^{g_{j}+\frac{a}{2}} H I I_{\theta j}\left(R_{m}, \theta\right) \cos (n p \theta) d \theta(46)$

The other equations are the same and the system of equations to be solved is now constituted from 12 equations with 12 unknowns $A 1_{n}$, $A 2_{n}, A 3_{n}, A 4_{n}, A 5_{j, 0}, A 6_{j, 0}, A 5_{j, m}, A 6_{j, m}, A 7_{n}, A 9_{n}, C_{i, 0}$ and $C_{i, m}$.

\section{ELECTROMAGNETIC PERFORMANCES CALCULATION}

Prediction of global quantities (cogging torque, flux linkage, induced back-EMF, self inductance, mutual inductance and electromagnetic torque), allows the evaluation of machine performances. 


\subsection{Cogging Torque Calculation}

According to Maxwell stress tensor method, cogging torque $T_{c}$ is computed using the analytical expression

$$
T_{c}=\frac{2 p L u R_{g}^{2}}{\mu_{0}} \int_{0}^{\frac{\pi}{p}} B I r\left(R_{g}, \theta\right) B I_{\theta}\left(R_{g}, \theta\right) d \theta
$$

where $R_{g}$ is the radius of a circle placed at the middle of the air-gap and $L u$ is the axial length of the motor.

Open-circuit radial and tangential components of the flux density in the middle of air gap $B I_{r}\left(R_{g}, \theta\right)$ and $B I_{\theta}\left(R_{g}, \theta\right)$ are determined from Equations (2) and (6).

\subsection{Flux Linkage and Back-EMF Calculation}

For slotted structures of PM machines, computation of flux linkage and back-Emf with the method of winding function theory is not suitable. The method based on Stokes theorem using the vector potential in stator slots is used. First, we determine at a given rotor position $\theta_{r}$, the flux over each slot $i$ of cross section $S$. We have supposed that the current is uniformly distributed over the slot area, so the vector potential can be averaged over the slot area to represent the coil.

For the simplified model, we obtain:

$$
\varphi_{i}=\frac{L u}{S} \int_{\alpha_{i}-\frac{c}{2}}^{\alpha_{i}+\frac{c}{2}} \int_{R_{S}}^{r_{4}} A I I I_{i}(r, \theta) r d r d \theta
$$

where $S=\frac{c\left(r_{4}^{2}-R_{s}^{2}\right)}{2}$ is the surface of the stator slots (inner radius $R_{s}$ and outer radius $r_{4}$ ).

The vector potential $A I I I_{i}(r, \theta)$ is given by (4). The development of (48) gives

$$
\varphi_{i}=L u C_{i, 0}
$$

$-\frac{\mu_{0} J_{i} L u\left(R_{s}^{4}+\left(2-4 \ln \left(R_{s}\right)\right) r_{4}^{2} R_{s}^{2}+\left(4 \ln \left(r_{4}\right)-3\right) r_{4}^{4}\right)}{-8 r_{4}^{2}+8 R_{s}^{2}} . \quad$ For the exact model, we obtain:

$$
\varphi_{i}=\frac{L u}{S} \int_{\alpha_{i}-\frac{c}{2}}^{\alpha_{i}+\frac{c}{2}} \int_{r_{3}}^{r_{4}} A I I I_{i}(r, \theta) r d r d \theta
$$

where $S=\frac{c\left(r_{4}^{2}-r_{3}^{2}\right)}{2}$ is the surface of the stator slots (inner radius $r_{3}$ and outer radius $r_{4}$ ). In this case, Equation (49) is modified with replacing 
$R_{s}$ with $r_{3}$. Of course, the value of the integration constant $C_{i, 0}$ in (49) is not the same for the simplified and exact models.

Under no-load condition and for both models $\left(J_{i}=0\right)$, the flux over each slot becomes

$$
\varphi_{i}=L u C_{i, 0}
$$

The phase flux vector is given by

$$
\left[\begin{array}{c}
\psi_{a} \\
\psi_{b} \\
\psi_{c}
\end{array}\right]=N_{c} C^{\prime}\left[\varphi_{1} \varphi_{2} \ldots \varphi_{Q_{s}-1} \varphi_{Q_{s}}\right]
$$

where $C^{\prime}$ is the transpose of connecting matrix that represents the distribution of stator windings in the slots. The matrix connection between phase current and stator slots for one pole pair is given by

$$
C=\left[\begin{array}{cccccccccccc}
1 & 1 & 0 & 0 & 0 & 0 & -1 & -1 & 0 & 0 & 0 & 0 \\
0 & 0 & 0 & 0 & 1 & 1 & 0 & 0 & 0 & 0 & -1 & -1 \\
0 & 0 & -1 & -1 & 0 & 0 & 0 & 0 & 1 & 1 & 0 & 0
\end{array}\right]
$$

The studied three phases PM motors are fed with $120^{\circ}$ rectangular phase currents. The current density in stator slots is defined as

$$
J_{i}=\frac{N_{c}}{S} C^{T}\left[\begin{array}{lll}
I_{a} & I_{b} & I_{c}
\end{array}\right]
$$

where $N_{c}$ is the number of conductors and $I_{a}, I_{b}, I_{c}$ are the stator phase currents.

The vector of rotor double excitation current density with $N_{r}$ elements $\left(N_{r}\right.$ is the number of rotor slots) for the studied machine is defined as

$$
J_{r_{i} r}=\frac{N_{f} I_{f}}{S_{f}}[-1-1 \ldots 11]
$$

where $N_{f}$ is the number of conductors in rotor slot, $I_{f}$ the DC excitation current and $S_{f}$ the surface of rotor slot.

The surface or rotor slots is given by $S_{f}=\frac{\operatorname{cr}\left(R_{m}^{2}-r_{5}^{2}\right)}{2}$ for the simplified model, and by $S_{f}=\frac{\operatorname{cr}\left(r_{0}^{2}-r_{1}^{2}\right)}{2}$ for the exact model.

The three phase back-EMF vector is calculated by

$$
\left[\begin{array}{c}
E_{a} \\
E_{b} \\
E_{c}
\end{array}\right]=\Omega \frac{d}{d \theta_{r}}\left[\begin{array}{l}
\psi_{a} \\
\psi_{b} \\
\psi_{c}
\end{array}\right]
$$

where $\Omega$ is the rotor angular speed.

Flux linkage and back-EMF are also dependent on the value of excitation current. 


\subsection{Electromagnetic Torque Calculation}

Electromagnetic torque can be computed from the back-EMF by

$$
T_{e m}=\frac{E_{a} I_{a}+E_{b} I_{b}+E_{c} I_{c}}{\Omega}
$$

Equation (47) can also be used to predict electromagnetic torque (total torque) if the open circuit flux density is substituted by the on-load flux density.

\subsection{Self and Mutual Inductances Calculation}

Self and mutual inductances can be calculated from the magnetic energy:

$$
\begin{aligned}
L_{a} & =\frac{2 W_{a}}{I_{a}^{2}} \\
L_{a c} & =\frac{W_{a c}-W_{a}-W_{c}}{I_{a} I_{c}}
\end{aligned}
$$

where $W_{a}, W_{c}$ and $W_{a c}$ are the magnetic energies when the magnets are not magnetized and the machine is fed with $I_{a}$ only, $I_{c}$ only, and both $I_{a}$ and $I_{c}$, respectively.

For the simplified model, magnetic energy can be obtained by:

$$
W=\frac{L u}{2} \sum_{i=1}^{Q_{s}} \int_{R_{s}}^{r_{4}} \int_{\alpha_{i}-\frac{c}{2}}^{\alpha_{i}+\frac{c}{2}} A I I I_{i}(r, \theta) J_{i} r d r d \theta
$$

For the exact model, (60) becomes:

$$
W=\frac{L u}{2} \sum_{i=1}^{Q_{s}} \int_{r_{3}}^{r_{4}} \int_{\alpha_{i}-\frac{c}{2}}^{\alpha_{i}+\frac{c}{2}} A I I I_{i}(r, \theta) J_{i} r d r d \theta
$$

\section{RESULTS AND VALIDATION}

In order to show the accuracy of the simplified model versus the exact model which takes into account stator and rotor tooth-tips [16], we compare the magnetic field distribution and electromagnetic performances obtained with the two models. Double excitation and spoke-type permanent magnet machines are considered. The analytical results are also compared with those obtained by finite element simulations [17]. The main dimensions and parameters of the 
Table 1. Parameters of simplified model for parallel double excitation and spoke-type permanent-magnet motors.

\begin{tabular}{lcc}
\hline Parameter & Symbol & $\begin{array}{c}\text { Value } \\
\text { and unit }\end{array}$ \\
\hline Magnet remanence (Ferrite) & $B_{r}$ & $0.4 \mathrm{~T}$ \\
Relative recoil permeability of magnet & $\mu_{r}$ & 1.0 \\
Number of conductors per stator slot & $N_{c}$ & 12 \\
Peak phase current & $I_{m}$ & $12.5 \mathrm{~A}$ \\
DC excitation current & $I_{f}$ & $15 \mathrm{~A}$ \\
Number of conductors per rotor slot & $N_{f}$ & 10 \\
Number of stator slots & $Q_{s}$ & 36 \\
Stator slot opening width & $c$ & $5^{\circ}$ \\
Rotor slot opening width & $c_{r}$ & $5^{\circ}$ \\
Number of pole pairs & $p$ & 3 \\
Number of rotor excitation slots & $N_{r}$ & 12 \\
Internal radius of rotor slot & $r_{5}$ & $35.8 \mathrm{~mm}$ \\
External radius of stator slot & $r_{4}$ & $54.3 \mathrm{~mm}$ \\
Radius of the external stator surface & $R_{o}$ & $74.8 \mathrm{~mm}$ \\
Radius of the stator outer surface & $R_{s}$ & $45.3 \mathrm{~mm}$ \\
Radius of the rotor inner surface at the magnet surface & $R_{m}$ & $44.8 \mathrm{~mm}$ \\
Radius of the rotor inner surface at the magnet bottom & $R_{r}$ & $15 \mathrm{~mm}$ \\
Air-gap length & $g$ & $0.5 \mathrm{~mm}$ \\
Height of a magnet & $h_{m}$ & $29.8 \mathrm{~mm}$ \\
Height of stator and rotor slot & $h_{s}$ & $9 \mathrm{~mm}$ \\
Stack length & $L_{u}$ & $57 \mathrm{~mm}$ \\
Magnet opening (mechanical degrees) & $a$ & $14^{\circ}$ \\
Rotor speed & $\Omega_{2}$ & $157 \mathrm{rd} / \mathrm{s}$ \\
\hline
\end{tabular}

studied machines for the simplified model are given in Table 1 . The supplementary geometrical parameters for the exact model are given in Table 2.

\subsection{Parallel Double Excitation PM Motors}

The proposed simplified model (SM) contains 14 equations (see appendix) with 14 unknowns. The exact model (EM) which was presented in [16] is more complex and contains 26 equations. The solution of the system of equations gives the potential vector and the flux density in each subdomain. 
Radial and tangential components of the flux density due to PM, rotor DC excitation current and armature reaction current acting together (on-load condition) are given in Figs. 7 and 8. Differences between results obtained with the two analytical models are not important for the radial component of the flux density and are more important for the tangential component as shown in Fig. 8. Differences on the flux density waveforms between the simplified and exact analytical model depends on the tooth-tips opening compare to

Table 2. Supplementary parameters of exact model for parallel double excitation and spoke-type permanent-magnet motors.

\begin{tabular}{lcc}
\hline Parameter & Symbol & $\begin{array}{c}\text { Value } \\
\text { and unit }\end{array}$ \\
\hline External radius of rotor slot & $r_{0}$ & $42.8 \mathrm{~mm}$ \\
External radius of PM & $r_{2}$ & $42.8 \mathrm{~mm}$ \\
External radius of stator semi-slot & $r_{3}$ & $47.3 \mathrm{~mm}$ \\
Internal radius of rotor slot & $r_{1}$ & $33.8 \mathrm{~mm}$ \\
Stator semi-slot Opening & $d$ & $4^{\circ}$ \\
Rotor semi-slot Opening & $d r$ & $4^{\circ}$ \\
PM semi-slot Opening & $b$ & $13^{\circ}$ \\
External radius of stator slot & $r_{4}$ & $56.3 \mathrm{~mm}$ \\
Radius of the rotor inner surface at the magnet bottom & $R_{r}$ & $13 \mathrm{~mm}$ \\
\hline
\end{tabular}

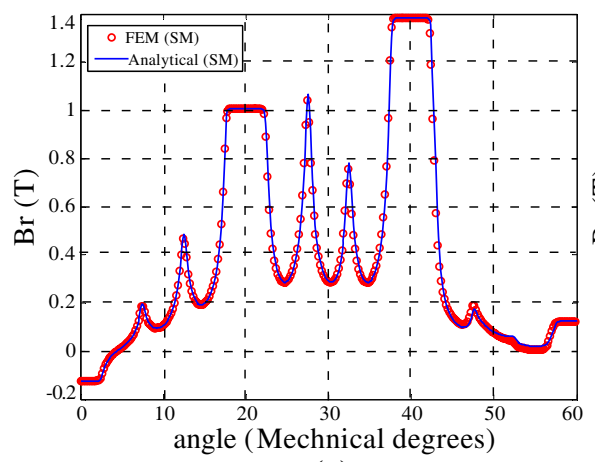

(a)

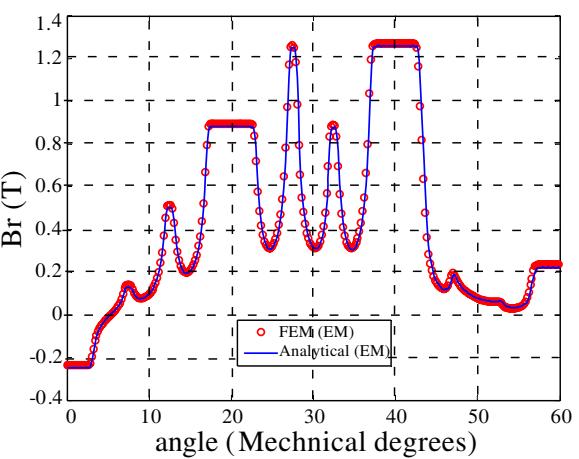

(b)

Figure 7. Radial component of the flux density for load condition (stator current, rotor excitation current and PM) in the $q$-axis rotor position. (a) Simplified model, (b) exact model. 


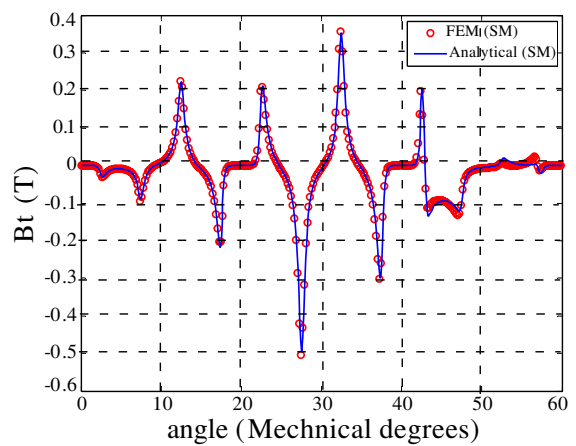

(a)

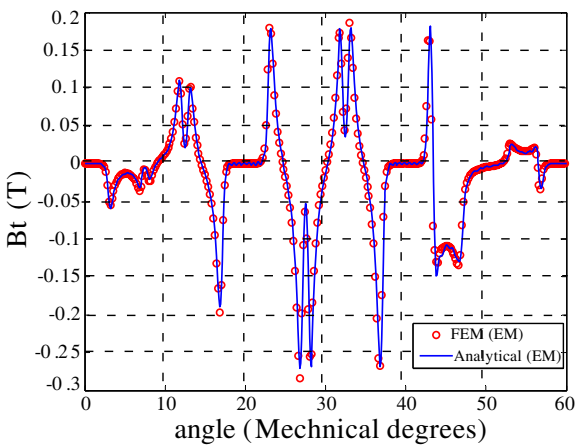

(b)

Figure 8. Tangential component of the flux density for load condition (stator current, rotor excitation current and $\mathrm{PM}$ ) in the $q$-axis rotor position. (a) Simplified model, (b) exact model.

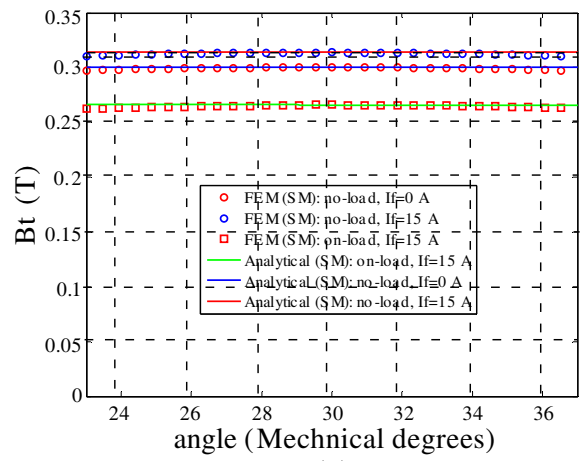

(a)

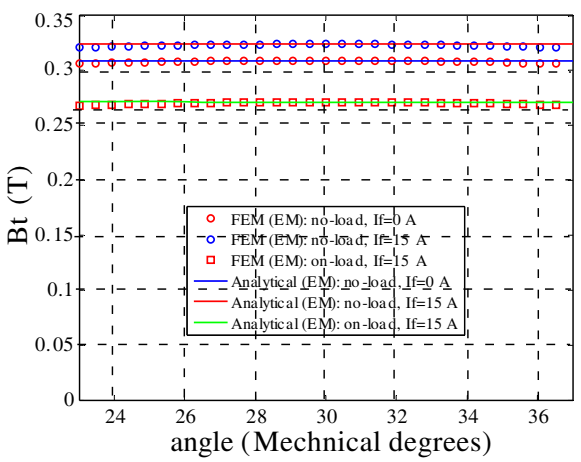

(b)

Figure 9. Tangential component of the flux density in the middle of the first magnet $(j=1)$ at no-load and on-load conditions. (a) Simplified model, (b) exact model.

the slots opening. For the studied example, we chose all the toothtips openings closer to slots openings. In the case of small tooth-tips openings compared to slot openings, we obtained significant differences between the two models (not presented here). The results presented here are in very good agreement with FEM for both simplified and exact models.

With the analytical model, we can predict the magnetic field distribution in all subdomains. Fig. 9 shows the tangential component of the flux density (radial flux density is null) in the middle of the 
first PM region $(j=1)$ for no-load and load conditions, and for two values of the $\mathrm{DC}$ excitation current. With these results, we can analyze the armature reaction and the DC excitation current effects in the demagnetization risk of the magnets. We can observe that the PM are not demagnetized, even under load condition. As known, the demagnetization risk occurs when the flux density in the magnet is approximately less than $0.1 \mathrm{~T}$ in the direction of magnetization.

From comparisons with FEM simulations, we can observe that

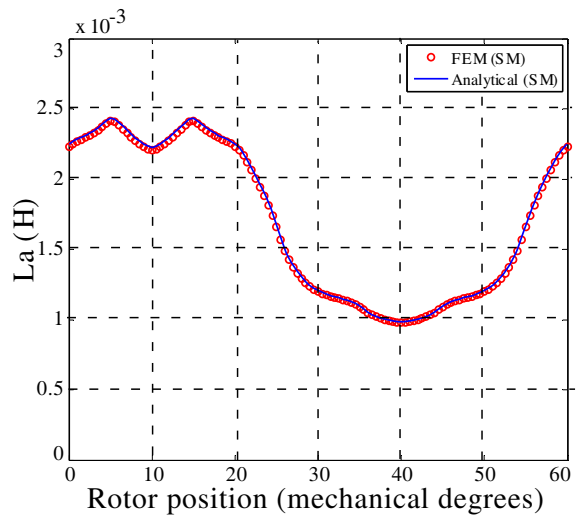

(a)

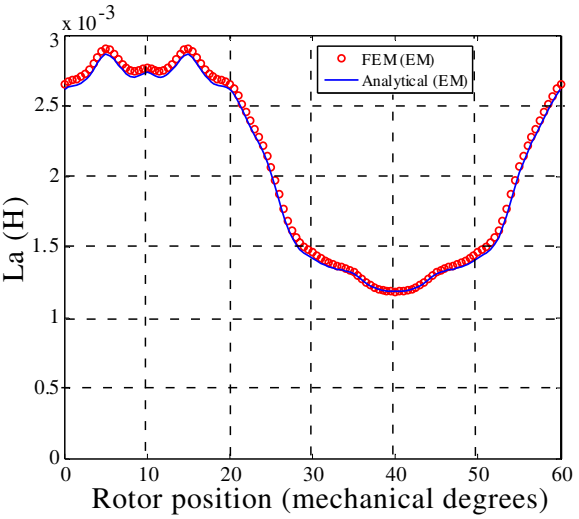

(b)

Figure 10. Phase A self-inductance. (a) Simplified model, (b) exact model.

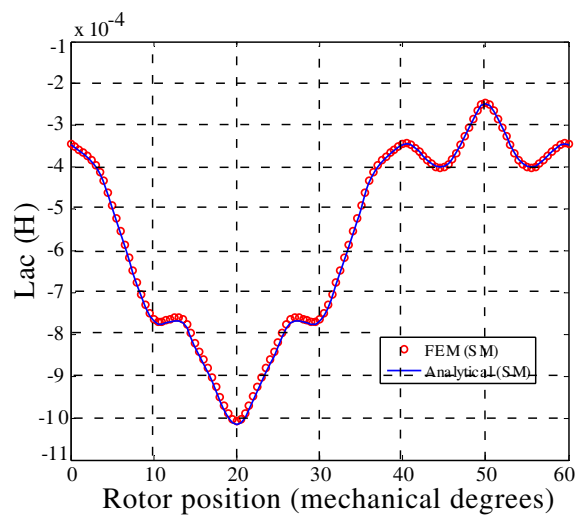

(a)

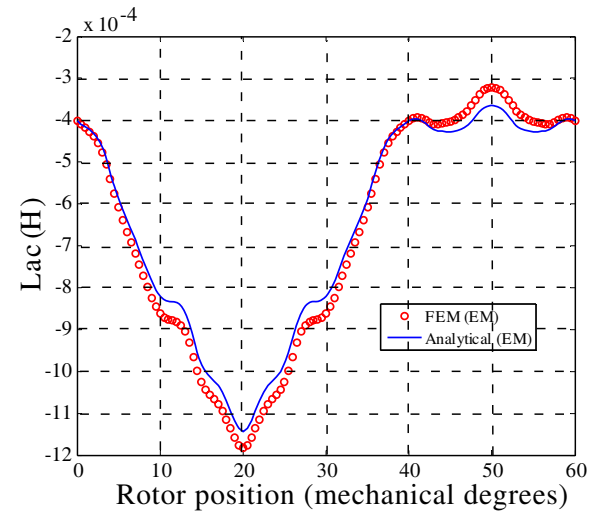

(b)

Figure 11. Mutual inductance between phases A and C. (a) Simplified model, (b) exact model. 


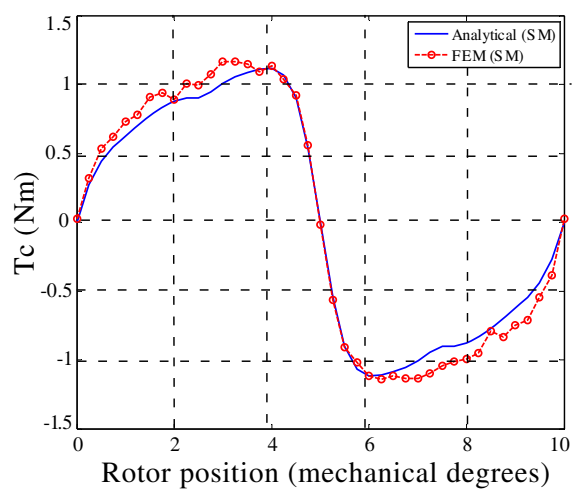

(a)

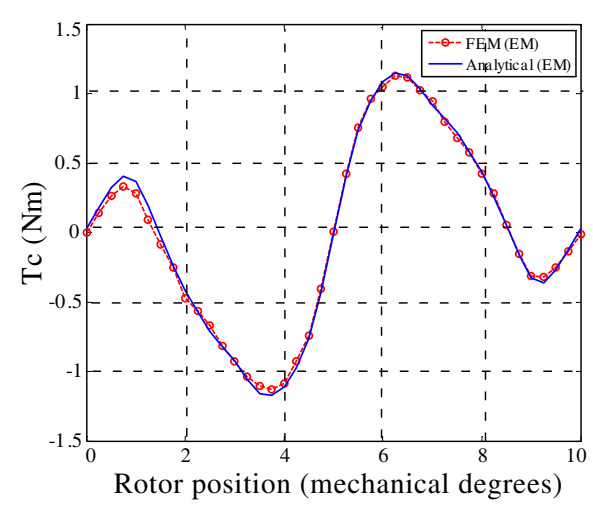

(b)

Figure 12. Cogging torque due to PM alone $\left(I_{f}=0 A\right)$. (a) Simplified model, (b) exact model.

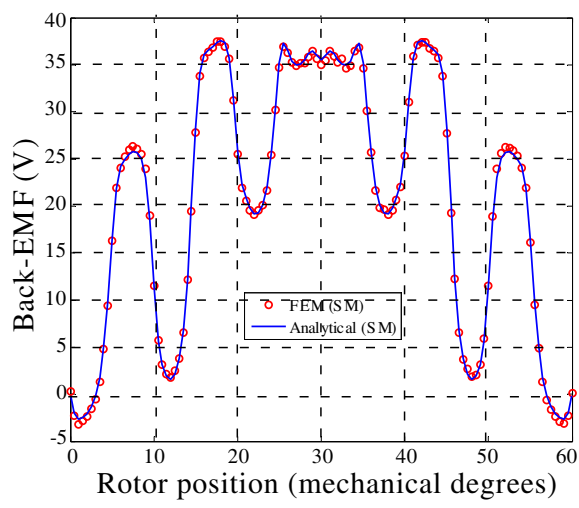

(a)

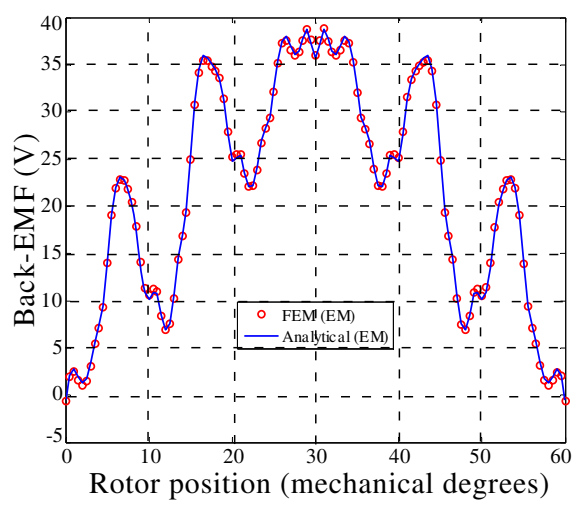

(b)

Figure 13. Back-Emf $\left(I_{f}=15 \mathrm{~A}\right)$. (a) Simplified model, (b) exact model.

analytical models (SM and EM) results agreed very well in the PM subdomain and are approximately the same for simplified and exact models.

Self and mutual inductances are given in Figs. 10 and 11. We can observe a very good agreement between exact and simplified analytical models and FEM results. From Fig. 10, we can determine the values of $q$-axis and $d$-axis self-inductance. The maximum value of the selfinductance corresponds to the $q$-axis rotor position $\left(\theta_{r}=10^{\circ}\right)$. The minimal value of the self-inductance corresponds to the $d$-axis rotor 


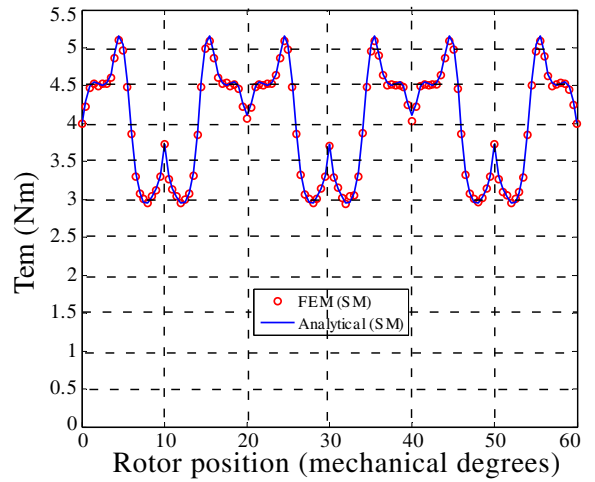

(a)

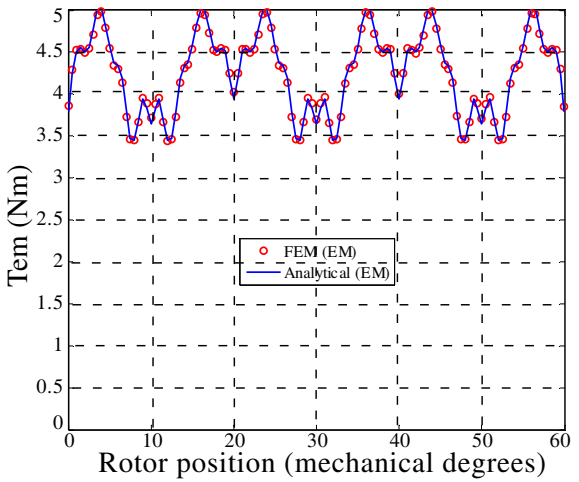

(b)

Figure 14. Electromagnetic torque $\left(I_{f}=15 \mathrm{~A}\right)$. (a) Simplified model, (b) exact model.

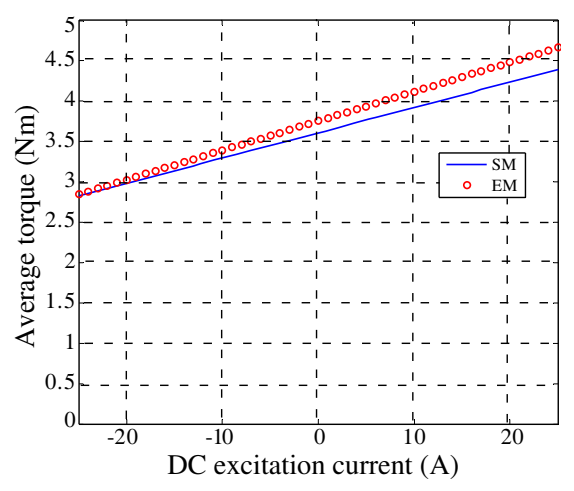

Figure 15. Average electromagnetic torque for different DC excitation current values.

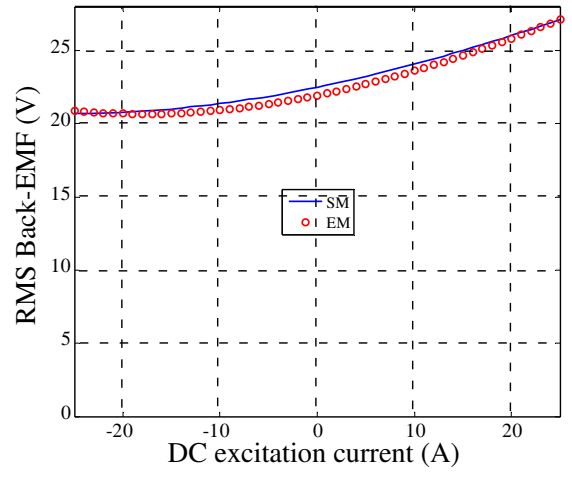

Figure 16. RMS back-Emf for different DC excitation current values.

position $\left(\theta_{r}=40^{\circ}\right)$. To determine the mutual inductance, the machine is fed with two-phase stator currents. The $q$-axis and $d$-axis rotor positions in this case corresponds to $\theta_{r}=20^{\circ}$ and $\theta_{r}=50^{\circ}$ respectively (Fig. 11). It can be seen from the comparison between simplified and exact models results (Fig. 10) that we have the same waveforms for the self-inductance with a difference of approximately $0.5 \mathrm{mH}$. As expected, the exact model gives a higher value of the self-inductance. This is due to the lower equivalent air-gap dimension caused by the presence of the tooth-tips. For mutual inductance (Fig. 11), this difference in amplitude is approximately $0.2 \mathrm{mH}$. There is a small difference in 
amplitude between exact analytical model and exact FEM model as shown in Fig. 11(b). This difference is due to the number of harmonics limitation used in the exact analytical model. This limitation is discussed in [16] and [18].

In control process, rotor DC excitation current can be set to zero, negative or positive values in order to increase or decrease electromagnetic torque, flux linkage and back-Emf. Cogging torque is also dependent on the value of the excitation current. We can observe from Figs. 12, 13 and 14 that exact model gives approximately the same amplitude compared to simplified model with a different waveform for cogging torque, back-emf and electromagnetic torque which is due to the presence of stator and rotor tooth-tips for the exact model. The results from exact and simplified analytical models are in very good agreement with the results obtained with simplified and exact FEM models.

Using the simplified and exact analytical models, the impact of the DC excitation current $I_{f}$ on the electromagnetic performances of the studied parallel double excitation PM motor is presented here. Average torque and back-Emf control capability are shown in Figs. 15 and 16. The study is done for $I_{f}$ ranging from $-25 \mathrm{~A}$ to $25 \mathrm{~A}$. We can observe that back-Emf and average electromagnetic torque increase with DC excitation current increase. Simplified and exact analytical models give approximately the same values with small differences for average torque for large values of DC excitation current.

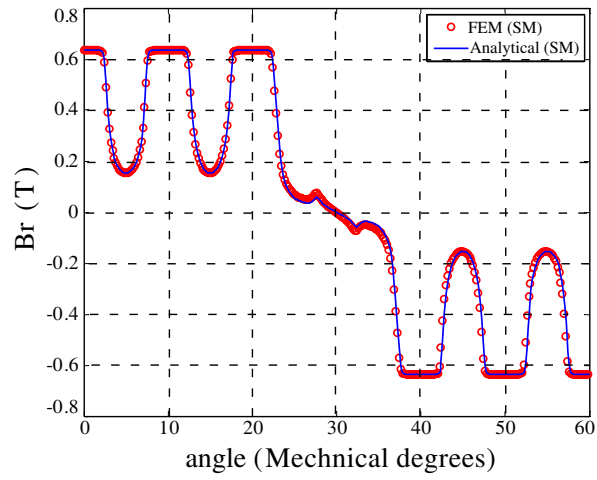

(a)

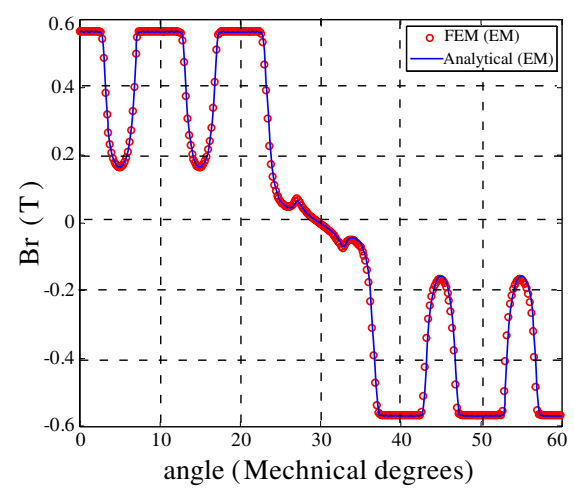

(b)

Figure 17. Radial component of the flux density due to PM alone. (a) Simplified model, (b) exact model. 


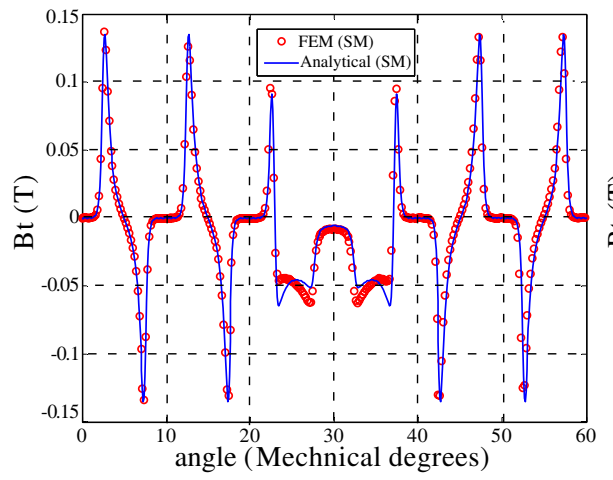

(a)

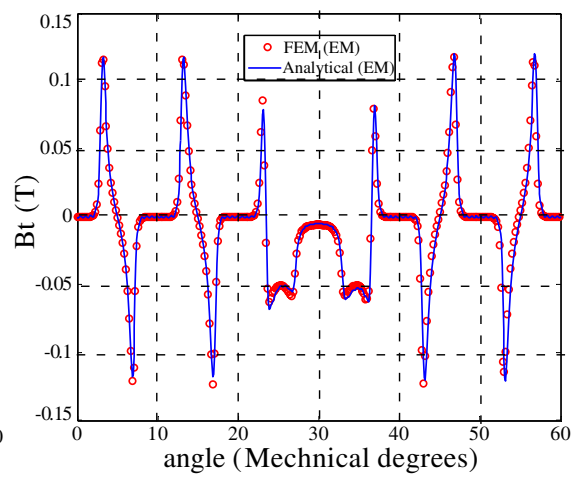

(b)

Figure 18. Tangential component of the flux density due to PM alone. (a) Simplified model, (b) exact model.

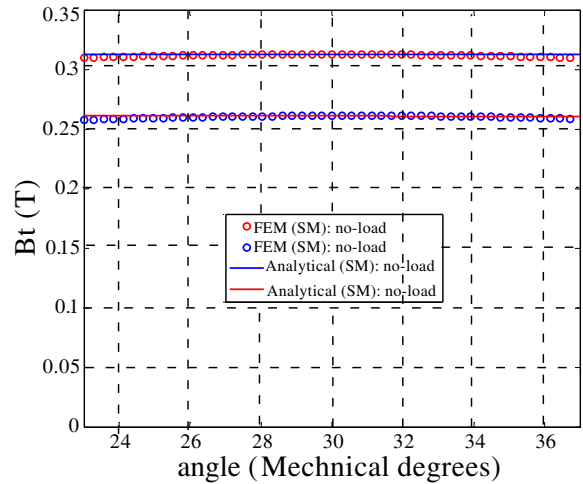

(a)

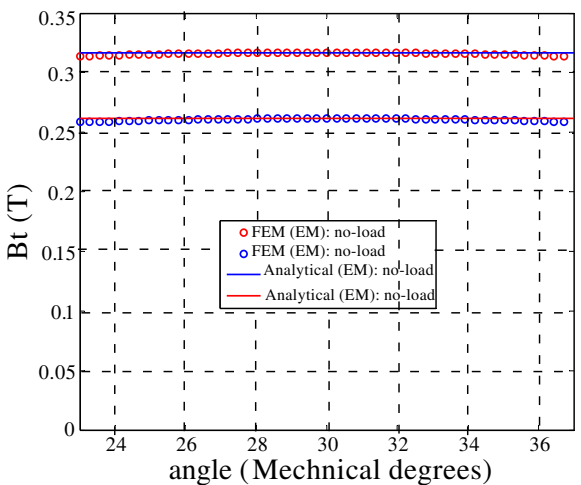

(b)

Figure 19. Tangential component of the flux density at no load and on-load conditions in the middle of the first magnet $(j=1)$. (a) Simplified model, (b) exact model

\subsection{Spoke-type PM Motors}

Analytical simplified model presented in this paper for the spoke-type PM motor contains 12 equations with 12 unknowns. The exact model presented by the authors in [16] included 20 equations. The solution of the system of linear equations leads to the vector potential and flux density in each subdomain. Radial and tangential components of the flux density due to permanent magnets acting alone are shown in Figs. 17 and 18, for simplified and exact analytical models and for FEM simulations. Both analytical models give approximately the 
same results for the studied machine where rotor and stator tooth-tips openings are closer to rotor and stator slots openings.

To study the effect of armature reaction on the demagnetization risk of ferrite magnets, we show in Fig. 19 the tangential component of the flux density (radial flux density is null) in the middle of the first PM subdomain. As shown, the demagnetization risk is avoided at no-load and on-load conditions. Simplified and exact analytical models give the same results. Once again, analytical results are in good agreement with those obtained by FEM for both simplified and exact models.

Self and mutual inductances variations with rotor position are

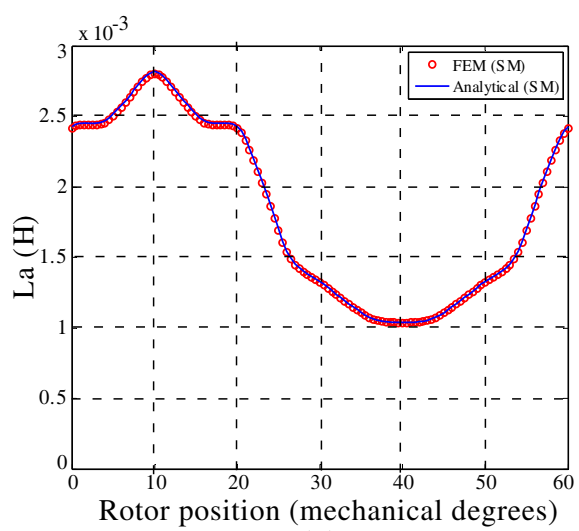

(a)

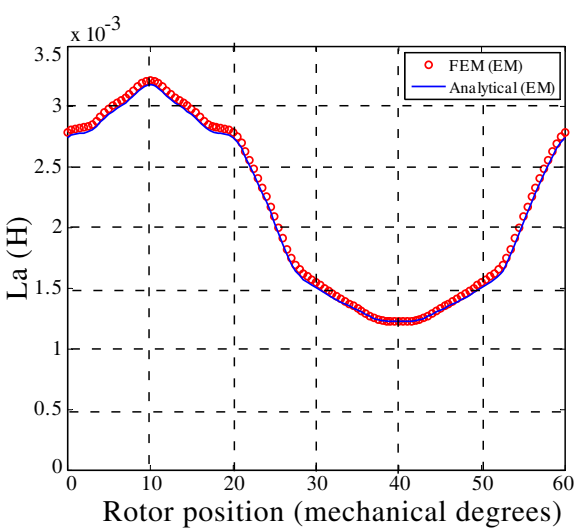

(b)

Figure 20. Phase A self inductance. (a) Simplified model, (b) exact model.

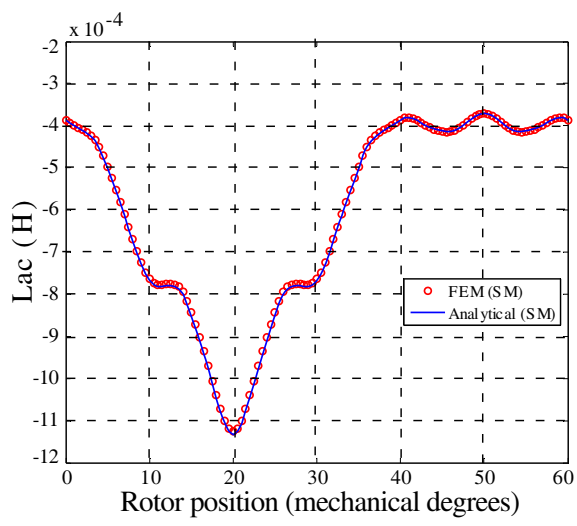

(a)

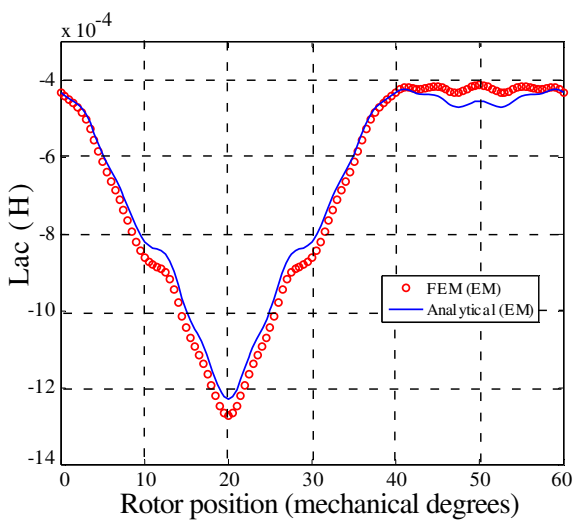

(b)

Figure 21. Mutual inductance between phase A and C. (a) Simplified model, (b) exact model. 


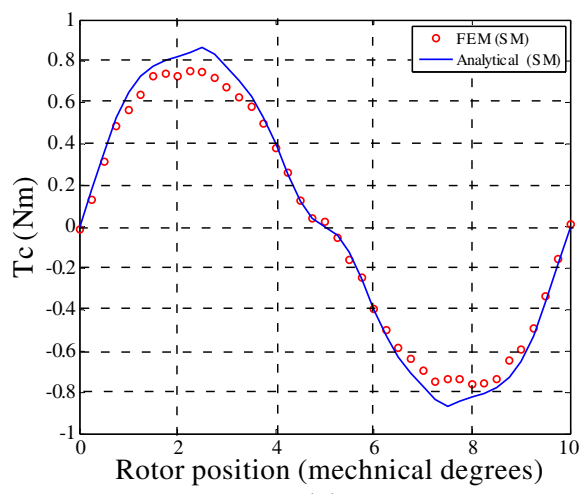

(a)

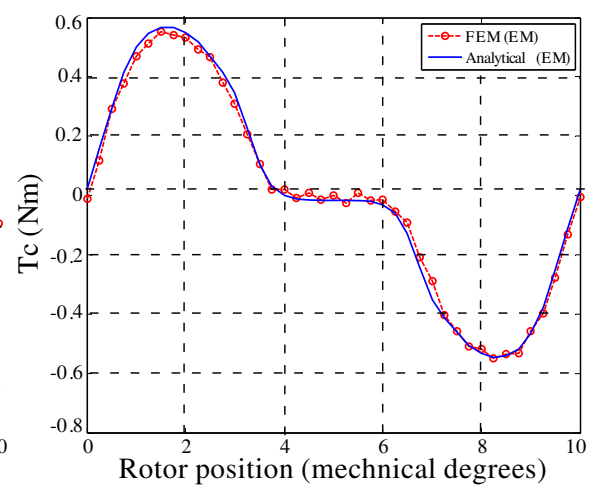

(b)

Figure 22. Cogging torque. (a) Simplified model, (b) exact model.

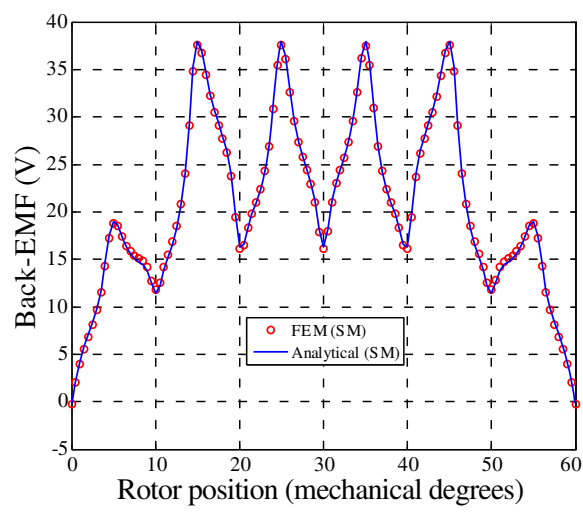

(a)

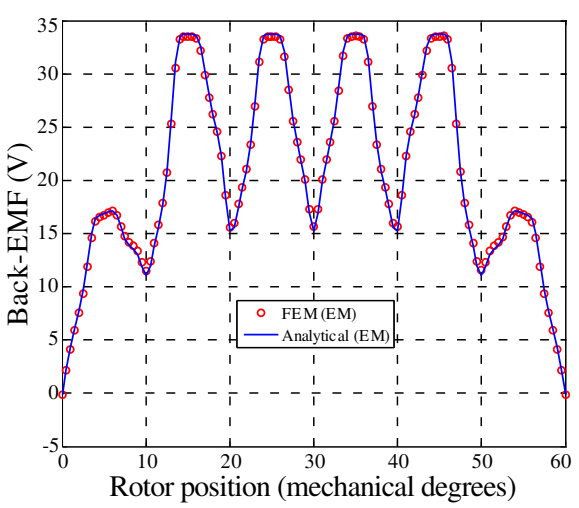

(b)

Figure 23. Emf. (a) Simplified model, (b) exact model.

shown in Figs. 20 and 21. Both results obtained from analytical models and FEM are in excellent agreement. From Fig. 20, we can determine the values of $q$-axis and $d$-axis self inductances. $Q$-axis self inductance (maximal inductance) corresponds to $\theta_{r}=10^{\circ}$ (rotor position) and $d$-axis self inductance (minimal inductance) corresponds to $\theta_{r}=40^{\circ}$. When the machine is fed with two-phase stator current, $q$-axis and $d$-axis rotor positions are located at $\theta_{r}=20^{\circ}$ and $\theta_{r}=50^{\circ}$ respectively (Fig. 21). It can be seen from Figs. 20 and 21 a difference of approximately $0.5 \mathrm{mH}$ when we compare the amplitudes of self and mutual inductances for simplified and exact model. The mutual inductance variation with rotor position (Fig. 21) obtained with the analytical exact model presents a small difference with FEM (EM). This is due to the limiting number of harmonics used in the calculation 


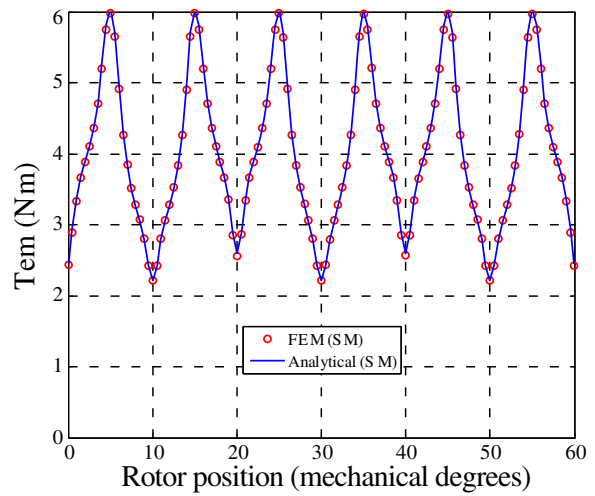

(a)

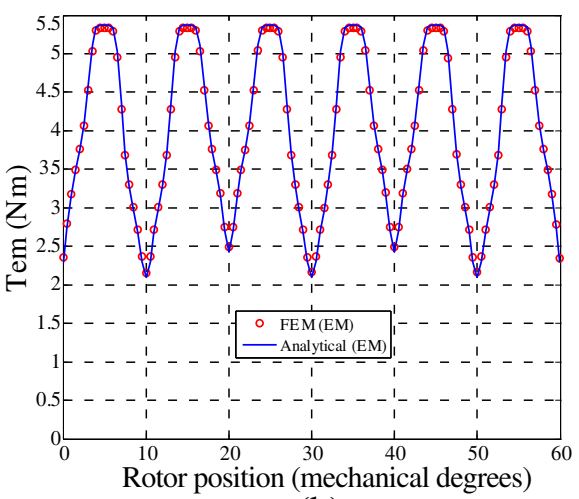

(b)

Figure 24. Electromagnetic torque. (a) Simplified model, (b) exact model.

as discussed in [16] and [18].

In Fig. 22, we show that the peak value of cogging torque is smaller than in parallel double excitation machine. This is due to the absence of rotor slots (DC current excitation) for spoke-type machine. The results obtained with FEM and with analytical models (SM and EM) are in very good agreement. We can observe that the cogging torque (Fig. 22(b)) obtained with the exact model, presents a smaller peak value and not the same waveform than the one obtained with the simplified analytical model (Fig. 22(a)). This result can be explain by the presence of stator and rotor tooth-tips for the exact model.

Analytical prediction of back-EMF and electromagnetic torque are shown in Figs. 23 and 24. The results are in good agreement with those issued from FEM. Slight differences in amplitude and waveform can be observed between simplified and exact model. This is due to the rotor and stator slots tooth-tips for the exact model.

\section{CONCLUSION}

In this paper, we have proposed simplified analytical model for parallel double excitation and spoke-type PM machines. Compared to our previous work [16], the proposed model doesn't take into account the stator and rotor tooth-tips and the exact shape of polar pieces. The simplified models need fewer equations for the predictions of magnetic field. The proposed analytical models have been used to predict magnetic field distribution and electromagnetic performances for double excitation and spoke-type PM machines. The Accuracy of analytical models has been verified with finite element simulations 
for the air-gap and PM subdomains. In comparison with radial surface-mounted PM motors where the effect of stator slot tooth-tips doesn't modify highly the waveform and amplitude of magnetic field distribution even when the tooth-tips opening are smaller than the slots opening [6], it is not the case for parallel double excitation and spoketype PM motors which have tooth-tips both in the rotor and stator sides. For this type of machines, the effect of stator, rotor and PM tooth-tips can modify highly the amplitude and waveform of magnetic field distribution and electromagnetic performances when rotor, stator and PM tooth-tips opening is smaller than slots opening, due to the mutual influence between stator and rotor slots.

The demagnetization risk of ferrite magnets has been analyzed with the proposed models. We have shown that the DC excitation current and the armature reaction reduce the flux density in the magnets but without demagnetization risk.

\section{APPENDIX A.}

Fourier series coefficients of general solution in different regions of parallel double excitation permanent magnet machines are determined by resolution of a system of equations. Some of those equations are detailed as follows.

From Equation (31), we get

$$
\begin{aligned}
A 5_{j, 0}+A 6_{j, 0} \ln \left(R_{r}\right)-M_{j} \mu_{0} R_{r}= & \frac{1}{a} \sum_{n=1}^{\infty}\left(A 7_{n} R_{r}^{n p}\right) \int_{g_{j}-\frac{a}{2}}^{g_{j}+\frac{a}{2}} \sin (n p \theta) d \theta \\
& +\frac{1}{a} \sum_{n=1}^{\infty}\left(A 9_{n} R_{r}^{n p}\right) \int_{g_{j}-\frac{a}{2}}^{g_{j}+\frac{a}{2}} \cos (n p \theta) d \theta(\mathrm{A} 1)
\end{aligned}
$$

Development of Equation (32) gives:

$$
\begin{aligned}
& A 5_{j, m} R_{r}^{-\frac{m \pi}{a}}+A 6_{j, m} R_{r}^{\frac{m \pi}{a}} \\
= & \frac{2}{a} \sum_{n=1}^{\infty}\left(A 7_{n} R_{r}^{n p}\right) \cdot \int_{g_{j}-\frac{a}{2}}^{g_{j}+\frac{a}{2}} \sin (n p \theta) \cos \left(\frac{m \pi}{a}\left(\theta-g_{j}+\frac{a}{2}\right)\right) d \theta \\
+ & \frac{2}{a} \sum_{n=1}^{\infty}\left(A 9_{n} R_{r}^{n p}\right) \cdot \int_{g_{j}-\frac{a}{2}}^{g_{j}+\frac{a}{2}} \cos (n p \theta) \cos \left(\frac{m \pi}{a}\left(\theta-g_{j}+\frac{a}{2}\right)\right) d \theta
\end{aligned}
$$


From Equation (33), we have:

$$
\begin{aligned}
& \left(\frac{n p}{\mu_{0}}\right)\left(-A 7_{n} R_{r}^{n p-1}\right) \\
= & \frac{1}{\pi \mu_{0} \mu_{r}} \sum_{j=1}^{2 p} \sum_{m=1}^{\infty}\left(\frac{m \pi}{a} A 5_{j, m} R_{r}^{-\frac{m \pi}{a}-1}-\frac{m \pi}{a} A 6_{j, m} R_{r}^{\frac{m \pi}{a}-1}\right) \\
& \cdot \int_{g_{j}-\frac{a}{2}} \sin (n p \theta) \cos \left(\frac{m \pi}{a}\left(\theta-g_{j}+\frac{a}{2}\right)\right) d \theta \\
& -\left(\frac{1}{\pi \mu_{0} \mu_{r}}\right) \sum_{j=1}^{2 p} \frac{A 6_{j, 0}}{R_{r}} \int_{g_{j}-\frac{a}{2}}^{g_{j}+\frac{a}{2}} \sin (n p \theta) d \theta
\end{aligned}
$$

Equation (34) gives

$$
\begin{aligned}
& \left(\frac{n p}{\mu_{0}}\right)\left(-A 9_{n} R_{r}^{n p-1}\right) \\
= & \frac{1}{\pi \mu_{0} \mu_{r}} \sum_{j=1}^{2 p} \sum_{m=1}^{\infty}\left(\frac{m \pi}{a} A 5_{j, m} R_{r}^{-\frac{m \pi}{a}-1}-\frac{m \pi}{a} A 6_{j, m} R_{r}^{\frac{m \pi}{a}-1}\right) \\
& \cdot \int_{g_{j}-\frac{a}{2}}^{g_{j}} \cos (n p \theta) \cos \left(\frac{m \pi}{a}\left(\theta-g_{j}+\frac{a}{2}\right)\right) d \theta \\
& -\left(\frac{1}{\pi \mu_{0} \mu_{r}}\right) \sum_{j=1}^{2 p} \frac{A 6_{j, 0}}{R_{r}} \int_{g_{j}-\frac{a}{2}}^{g_{j}+\frac{a}{2}} \cos (n p \theta) d \theta
\end{aligned}
$$

Equation (35) gives

$$
\begin{aligned}
& A 5_{j, 0}+A 6_{j, 0} \ln \left(R_{m}\right)-M_{j} \mu_{0} R_{m} \\
= & \frac{1}{a} \sum_{n=1}^{\infty}\left(A 1_{n} R_{m}^{n p}+A 2_{n} R_{m}^{-n p}\right) \int_{g_{j}-\frac{a}{2}}^{g_{j}+\frac{a}{2}} \sin (n p \theta) d \theta \\
& +\frac{1}{a} \sum_{n=1}^{\infty}\left(A 3_{n} R_{m}^{n p}+A 4_{n} R_{m}^{-n p}\right) \int_{g_{j}-\frac{a}{2}}^{g_{j}+\frac{a}{2}} \cos (n p \theta) d \theta
\end{aligned}
$$


Equation (36) gives

$$
\begin{aligned}
& A 5_{j, m} R_{m}^{-\left(\frac{m \pi}{a}\right)}+A 6_{j, m} R_{m}^{\left(\frac{m \pi}{a}\right)} \\
= & \frac{2}{a} \sum_{n=1}^{\infty}\left(A 1_{n} R_{m}^{n p}+A 2_{n} R_{m}^{-n p}\right) \cdot \int_{g_{j}-\frac{a}{2}}^{g_{j}+\frac{a}{2}} \sin (n p \theta) \cos \left(\frac{m \pi}{a}\left(\theta-g_{j}+\frac{a}{2}\right)\right) d \theta \\
+ & \frac{2}{a} \sum_{n=1}^{\infty}\left(A 3_{n} R_{m}^{n p}+A 4_{n} R_{m}^{-n p}\right) \cdot \int_{g_{j}-\frac{a}{2}}^{g_{j}} \cos (n p \theta) \cos \left(\frac{m \pi}{a}\left(\theta-g_{j}+\frac{a}{2}\right)\right) d \theta(\mathrm{A} 6)
\end{aligned}
$$

Equation (37) development gives

$$
\begin{aligned}
C 1_{i r, 0}+\frac{1}{2} \mu_{0} J r_{i r} r_{5}^{2} \ln \left(R_{m}\right)-\frac{1}{4} \mu_{0} J r_{i r} R_{m}^{2} \\
=\frac{1}{c r} \sum_{n=1}^{\infty}\left(A 1_{n} R_{m}^{n p}+A 2_{n} R_{m}^{-n p}\right) \int_{\beta_{i r}-\frac{c r}{2}}^{\beta_{i r}+\frac{c r}{2}} \sin (n p \theta) d \theta \\
+\frac{1}{c r} \sum_{n=1}^{\infty}\left(A 3_{n} R_{m}^{n p}+A 4_{n} R_{m}^{-n p}\right) \int_{\beta_{i r}-\frac{c r}{2}}^{\beta_{i r}+\frac{c r}{2}} \cos (n p \theta) d \theta
\end{aligned}
$$

Equation (38) development gives

$$
\begin{aligned}
& C 1_{i r, m}\left(\left(\frac{R_{m}}{r_{5}}\right)^{\frac{m \pi}{c r}}-\left(\frac{R_{m}}{r_{5}}\right)^{-\frac{m \pi}{c r}}\right) \\
& =\frac{2}{c r} \sum_{n=1}^{\infty}\left(A 1_{n} R_{m}^{n p}+A 2_{n} R_{m}^{-n p}\right) \cdot \int_{\beta_{i r}-\frac{c r}{2}}^{\beta_{i r}+\frac{c r}{2}} \sin (n p \theta) \cos \left(\frac{m \pi}{c r}\left(\theta-\beta_{i r}+\frac{c r}{2}\right)\right) d \theta \\
& +\frac{2}{c r} \sum_{n=1}^{\infty}\left(A 3_{n} R_{m}^{n p}+A 4_{n} R_{m}^{-n p}\right) \cdot \int_{\beta_{i r}-\frac{c r}{2}}^{\cos }(n p \theta) \cos \left(\frac{m \pi}{c r}\left(\theta-\beta_{i r}+\frac{c r}{2}\right)\right) d \theta(\mathrm{A} 8
\end{aligned}
$$


Equation (39) development gives

$$
\begin{aligned}
& \frac{n p}{\mu_{0}}\left(-A 1_{n} R_{m}^{n p-1}+A 2_{n} R_{m}^{-n p-1}\right) \\
& =\frac{1}{\pi} \sum_{j=1}^{2 p} \sum_{m=1}^{\infty} \frac{m \pi}{a \mu_{0} \mu_{r}}\left(A 5_{j, m} R_{m}^{-\frac{m \pi}{a}-1}-A 6_{j, m} R_{m}^{\frac{m \pi}{a}-1}\right) \\
& g_{j}+\frac{a}{2} \\
& \text {. } \int \cos \left(\frac{m \pi}{a}\left(\theta-g_{j}+\frac{a}{2}\right)\right) \sin (n p \theta) d \theta \\
& g_{j}-\frac{a}{2} \\
& -\frac{1}{\pi \mu_{0} \mu_{r}} \sum_{j=1}^{2 p} \frac{A 6_{j, 0}}{R_{m}} \int_{g_{j}-\frac{a}{2}}^{g_{j}+\frac{a}{2}} \sin (n p \theta) d \theta \\
& -\frac{1}{\pi \mu_{0}} \sum_{i r=1}^{N_{r}} \sum_{m=1}^{\infty} C 1_{i r, m} \frac{m \pi}{R_{m} c r}\left(\left(\frac{R_{m}}{r_{5}}\right)^{\frac{m \pi}{c r}}+\left(\frac{R_{m}}{r_{5}}\right)^{-\frac{m \pi}{c r}}\right) \\
& \beta_{i r}+\frac{c r}{2} \\
& \int_{\beta_{i r}} \cos \left(\frac{m \pi}{c r}\left(\theta-\beta_{i r}+\frac{c r}{2}\right)\right) \sin (n p \theta) d \theta \\
& \beta_{i r}-\frac{c r}{2} \\
& +\frac{1}{\pi \mu_{0}} \sum_{i r=1}^{N_{r}}\left(-\frac{1}{2} \frac{\mu_{0} J r_{i r} r_{5}^{2}}{R_{m}}+\frac{1}{2} \mu_{0} J r_{i r} R_{m}\right) \cdot \int_{\beta_{i r}-\frac{c r}{2}}^{\beta_{i r}+\frac{c r}{2}} \sin (n p \theta) d \theta(\mathrm{A} 9)
\end{aligned}
$$

Equation (40) development gives

$$
\begin{aligned}
& \frac{n p}{\mu_{0}}\left(-A 3_{n} R_{m}^{n p-1}+A 4_{n} R_{m}^{-n p-1}\right) \\
= & \frac{1}{\pi} \sum_{j=1}^{2 p} \sum_{m=1}^{\infty} \frac{m \pi}{a \mu_{0} \mu_{r}}\left(A 5_{j, m} R_{m}^{-\frac{m \pi}{a}-1}-A 6_{j, m} R_{m}^{\frac{m \pi}{a}-1}\right) \\
& \cdot \int_{g_{j}+\frac{a}{2}}^{\cos }\left(\frac{m \pi}{a}\left(\theta-g_{j}+\frac{a}{2}\right)\right) \cos (n p \theta) d \theta \\
& -\frac{1}{\pi \mu_{0} \mu_{r}} \sum_{j=1}^{2 p} \frac{A 6_{j, 0}}{R_{m}} \int_{g_{j}-\frac{a}{2}}^{2} \cos (n p \theta) d \theta
\end{aligned}
$$




$$
\begin{aligned}
& -\frac{1}{\pi \mu_{0}} \sum_{i r=1}^{N_{r}} \sum_{m=1}^{\infty} C 1_{i r, m} \frac{m \pi}{R_{m} c r}\left(\left(\frac{R_{m}}{r_{5}}\right)^{\frac{m \pi}{c r}}+\left(\frac{R_{m}}{r_{5}}\right)^{-\frac{m \pi}{c r}}\right) \\
& \int_{\beta_{i r}-\frac{c r}{2}}^{\beta_{i r}+\frac{c r}{2}} \cos \left(\frac{m \pi}{c r}\left(\theta-\beta_{i r}+\frac{c r}{2}\right)\right) \cos (n p \theta) d \theta \\
& +\frac{1}{\pi \mu_{0}} \sum_{i r=1}^{N_{r}}\left(-\frac{1}{2} \frac{\mu_{0} J r_{i r} r_{5}^{2}}{R_{m}}+\frac{1}{2} \mu_{0} J r_{i r} R_{m}\right)_{\beta_{i r}-\frac{c r}{2}}^{\beta_{i r}+\frac{c r}{2}} \cos (n p \theta) d \theta(
\end{aligned}
$$

Equation (41) development gives

$$
\begin{aligned}
& C_{i, 0}+\frac{1}{2} \mu_{0} J_{i} r_{4}^{2} \ln \left(R_{s}\right)-\frac{1}{4} \mu_{0} J_{i} R_{s}^{2} \\
= & \frac{1}{c} \sum_{n=1}^{\infty}\left(A 1_{n} R_{s}^{n p}+A 2_{n} R_{s}^{-n p}\right) \int_{\alpha_{i}-\frac{c}{2}}^{\alpha_{i}+\frac{c}{2}} \sin (n p \theta) d \theta \\
& +\frac{1}{c} \sum_{n=1}^{\infty}\left(A 3_{n} R_{s}^{n p}+A 4_{n} R_{s}^{-n p}\right) \int_{\alpha_{i}-\frac{c}{2}}^{\alpha_{i}+\frac{c}{2}} \cos (n p \theta) d \theta
\end{aligned}
$$

Equation (42) development gives

$$
\begin{aligned}
& C_{i, m}\left(\left(\frac{R_{s}}{r_{4}}\right)^{\frac{m \pi}{c}}-\left(\frac{R_{s}}{r_{4}}\right)^{-\frac{m \pi}{c}}\right) \\
= & \frac{2}{c} \sum_{n=1}^{\infty}\left(A 1_{n} R_{s}^{n p}+A 2_{n} R_{s}^{-n p}\right) \cdot \int_{\alpha_{i}-\frac{c}{2}}^{\alpha_{i}+\frac{c}{2}} \cos \left(\frac{m \pi}{c}\left(\theta-\alpha_{i}+\frac{c}{2}\right)\right) \sin (n p \theta) d \theta \\
+ & \frac{2}{c} \sum_{n=1}^{\infty}\left(A 3_{n} R_{s}^{n p}+A 4_{n} R_{s}^{-n p}\right) \cdot \int_{\alpha_{i}-\frac{c}{2}}^{\alpha_{i}+\frac{c}{2}} \cos \left(\frac{m \pi}{c}\left(\theta-\alpha_{i}+\frac{c}{2}\right)\right) \cos (n p \theta) d \theta(\mathrm{A}
\end{aligned}
$$


Equation (43) development gives

$$
\begin{aligned}
& \frac{n p}{\mu_{0}}\left(-A 1_{n} R_{s}^{n p-1}+A 2_{n} R_{s}^{-n p-1}\right) \\
= & -\frac{1}{\pi \mu_{0}} \sum_{i=1}^{Q_{s}} \sum_{m=1}^{\infty} C_{i, m} \frac{m \pi}{c R_{s}}\left(\left(\frac{R_{s}}{r_{4}}\right)^{\frac{m \pi}{c}}+\left(\frac{R_{s}}{r_{4}}\right)^{-\frac{m \pi}{c}}\right) \\
& \cdot \int_{\alpha_{i}-\frac{c}{2}}^{\alpha_{i}+\frac{c}{2}} \cos \left(\frac{m \pi}{c}\left(\theta-\alpha_{i}+\frac{c}{2}\right)\right) \sin (n p \theta) d \theta \\
& +\frac{1}{\pi \mu_{0}} \sum_{i=1}^{Q_{s}}\left(-\frac{1}{2} \frac{\mu_{0} J_{i} r_{4}^{2}}{R_{s}}+\frac{1}{2} \mu_{0} J_{i} R_{s}\right) \cdot \int_{\alpha_{i}-\frac{c}{2}}^{\alpha_{i}+\frac{c}{2}} \sin (n p \theta) d \theta(\mathrm{A})
\end{aligned}
$$

Equation (44) development gives

$$
\begin{aligned}
& \frac{n p}{\mu_{0}}\left(-A 3_{n} R_{s}^{n p-1}+A 4_{n} R_{s}^{-n p-1}\right) \\
= & -\frac{1}{\pi \mu_{0}} \sum_{i=1}^{Q_{s}} \sum_{m=1}^{\infty} C_{i, m} \frac{m \pi}{c R_{s}}\left(\left(\frac{R_{s}}{r_{4}}\right)^{\frac{m \pi}{c}}+\left(\frac{R_{s}}{r_{4}}\right)^{-\frac{m \pi}{c}}\right) \\
& \int_{i}+\frac{c}{2} \\
& \int_{\alpha_{i}-\frac{c}{2}} \cos \left(\frac{m \pi}{c}\left(\theta-\alpha_{i}+\frac{c}{2}\right)\right) \cos (n p \theta) d \theta \\
& +\frac{1}{\pi \mu_{0}} \sum_{i=1}^{Q_{s}}\left(-\frac{1}{2} \frac{\mu_{0} J_{i} r_{4}^{2}}{R_{s}}+\frac{1}{2} \mu_{0} J_{i} R_{s}\right) \cdot \int_{\alpha_{i}-\frac{c}{2}}^{\alpha_{i}+\frac{c}{2}} \cos (n p \theta) d \theta(\mathrm{A} 14)
\end{aligned}
$$

The system of equations to solve in parallel double excitation PM motors is constituted by the 14 equations from (A1) to (A14) with the unknowns $A 1_{n}, A 2_{n}, A 3_{n}, A 4_{n}, A 5_{j, 0}, A 6_{j, 0}, A 5_{j, m}, A 6_{j, m}, A 7_{n}, A 9_{n}$, $C_{i, 0}, C_{i, m}, C 1_{i r, 0}, C 1_{i r, m}$. For spoke-type PM motors, Equations (A7) and (A8) are omitted and Equations (A9) and (A10) are modified as explained in Equations (45) and (46).

\section{REFERENCES}

1. Lubin, T., S. Mezani, and A. Rezzoug, "2D analytical calculation of magnetic field and electromagnetic torque for surface-inset permanent magnet motors," IEEE Trans. Magnetics., Vol. 48, No. 6, 2080-2091, June 2012. 
2. Zhu, Z. Q., L. J. Wu, and Z. P. Xia, "An accurate subdomain model for magnetic field computation in slotted surface-mounted permanent-magnet machines," IEEE Trans. Magnetics., Vol. 46, No. 4, 1100-1115, April 2010.

3. Lubin, T., S. Mezani, and A. Rezzoug, "2-D exact analytical model for surface-mounted permanent-magnet motors with semiclosed slots," IEEE Trans. Magnetics., Vol. 47, No. 2, 479-4929, February 2011.

4. Wu, L. J., Z. Q. Zhu, D. Staton, M. Popescu, and D. Hawkins, "An improved subdomain model for predicting magnetic field of surface-mounted permanent magnet machines accounting for tooth-tips," IEEE Trans. Magnetics., Vol. 47, No. 6, 1693-1704, June 2011.

5. Wu, L. J., Z. Q. Zhu, D. Staton, M. Popescu, and D. Hawkins, "Subdomain model for predicting armature reaction field of surface-mounted permanent-magnet machines accounting for tooth-tips," IEEE Trans. Magnetics., Vol. 47, No. 4, 812-822, April 2011.

6. Wu, L. J., Z. Q. Zhu, D. Staton, M. Popescu, and D. Hawkins, "Analytical prediction of electromagnetic performance of surfacemounted permanent magnet machines based on subdomain model accounting for tooth-tips," Electric Power Applications, IET, Vol. 5, No. 7, 597-609, 2011.

7. Jian, L., K. T. Chau, Y. Gong, C. Yu, and W. Li, "Analytical calculation of magnetic field in surface-inset permanent magnet motors," IEEE Trans. Magnetics., Vol. 45, No. 10, 4688-4691, October 2009.

8. Bali, H., Y. Amara, G. Barakat, R. Ibtiouen, and M. Gabsi, "Analytical modeling of open circuit magnetic field in wound field and series double excitation synchronous machines," IEEE Trans. Magnetics., Vol. 46, No. 10, 3802-3815, October 2010.

9. Jian, L., G. Xu, C. C. Mi, K. T. Chau, and C. C. Chan, "Analytical method for magnetic field calculation in a low-speed permanent-magnet harmonic machine," IEEE Trans. Energy Conversion., Vol. 26, No. 3, 862-870, September 2011.

10. Jian, L. and K. T. Chau, "Analytical calculation of magnetic field distribution in coaxial magnetic gears," Progress In Electromagnetics Research, Vol. 92, No. 7, 1-16, 2009.

11. Lubin, T., S. Mezani, and A. Rezzoug, "Improved analytical model for surface-mounted PM motors considering slotting effects and armature reaction," Progress In Electromagnetics Research B, Vol. 25, 293-314, 2010. 
12. Hlioui, S., L. Vido, Y. Amara, M. Gabsi, A. Miraoui, and M. Lécrivain, "Magnetic equivalent circuit model of a hybrid excitation synchronous machine," COMPEL: The International Journal for Computation and Mathematics in Electrical and Electronic Engineering, Vol. 27, No. 5, 1000-1015, 2008.

13. Lin, D., P. Zhou, C. Lu, and S. Lin, "Analytical prediction of cogging torque for spoke type permanent magnet machines," IEEE Trans. Magnetics., Vol. 48, No. 2, 1035-1038, February 2012.

14. Wu, L. J., Z. Q. Zhu, D. Staton, M. Popescu, and D. Hawkins, "Comparison of analytical models of cogging torque in surfacemounted PM machines," IEEE Trans. Magnetics., Vol. 59, No. 6, 2414-2425, June 2012.

15. Boughrara, K., D. Zarko, R. Ibtiouen, O. Touhami, and A. Rezzoug, "Magnetic field analysis of inset and surface mounted permanent magnet synchronous motors using Schwarz-Christoffel transformation," IEEE Trans. Magnetics., Vol. 45, No. 8, 31663178, August 2009.

16. Boughrara, K., R. Ibtiouen, and T. Lubin, "Analytical prediction of magnetic field in parallel double excitation and spoke-type permanent-magnet machines accounting for tooth-tips and shape of polar pieces," IEEE Trans. Magnetics., Vol. 48, No. 7, 21212137, July 2012.

17. Meeker, D. C., Finite Element Method Magnetics, Version 4.2, April 1, 2009 Build, http://www.femm.info.

18. Gysen, B. L. J., E. Ilhan, K. J. Meessen, J. J. H. Paulides, and E. A. Lomonova, "Modeling of flux switching permanent magnet machines with fourier analysis," IEEE Trans. Magnetics., Vol. 46, No. 6, 1499-1502, June 2010. 